\title{
miRNA-122 Protects Mice and Human Hepatocytes from Acetaminophen Toxicity by Regulating Cytochrome P450 Family 1 Subfamily A Member 2 and Family 2 Subfamily E Member 1 Expression
}

Vivek Chowdhary, ${ }^{*}$ Kun-yu Teng, ${ }^{*}$ Sharda Thakral, ${ }^{*}$ Bo Zhang, ${ }^{\dagger}$ Cho-hao Lin, ${ }^{*}$ Nissar Wani, ${ }^{\ddagger}$ Lei Bruschweiler-Li, ${ }^{\S}$ Xiaoli Zhang, Laura James, Dakai Yang, ${ }^{* *}$ Norman Junge, ${ }^{* *}$ Rafael Brüschweiler, ${ }^{\dagger \S \dagger \dagger}$ William M. Lee, ${ }^{\ddagger \dagger}$ and Kalpana Ghoshal

From the Departments of Pathology, ${ }^{*}$ Chemistry and Biochemistry, ${ }^{\dagger}$ Cancer Biology and Genetics, ${ }^{\ddagger}$ and Biological Chemistry and Pharmacology, ${ }^{\dagger \dagger}$ the Campus Chemical Instrument Center, ${ }^{\S}$ and the Center for Biostatistics, ${ }^{\AA}$ Department of Biomedical Informatics, The Ohio State University, Columbus, Ohio; the Department of Pediatrics," Arkansas Children's Hospital, Little Rock, Arkansas; the Department of Pediatric Gastroenterology and Hepatology, ** Hannover Medical School, Hannover, Germany; and the Department of Internal Medicine ${ }^{\ddagger}$ UT Southwestern Medical Center, Dallas, Texas

Accepted for publication August 17, 2017.

Address correspondence to Kalpana Ghoshal, Ph.D., Department of Pathology, The Ohio State University, Comprehensive Cancer Center, 646C TMRF Bldg., $420 \mathrm{~W}$ 12th Ave., Columbus, OH 43210; or William M. Lee, M.D., Digestive and Liver Disease Clinic, 1801 Inwood Rd., Sixth Floor, Ste. 102, Dallas, TX 75390-9083. E-mail: kalpana.ghoshal@osumc.edu or william.lee@utsouthwestern. edu.
Acetaminophen toxicity is a leading cause of acute liver failure (ALF). We found that miRNA-122 (miR-122) is down-regulated in liver biopsy specimens of patients with ALF and in acetaminophentreated mice. A marked decrease in the primary miR-122 expression occurs in mice on acetaminophen overdose because of suppression of its key transactivators, hepatocyte nuclear factor (HNF)- $4 \alpha$ and HNF6. More importantly, the mortality rates of male and female liver-specific miR-122 knockout (LKO) mice were significantly higher than control mice when injected i.p. with an acetaminophen dose not lethal to the control. LKO livers exhibited higher basal expression of cytochrome P450 family 2 subfamily E member 1 (CYP2E1) and cytochrome P450 family 1 subfamily A member 2 (CYP1A2) that convert acetaminophen to highly reactive $\mathrm{N}$-acetyl-p-benzoquinone imine. Upregulation of Cyp1a2 primary transcript and mRNA in LKO mice correlated with the elevation of aryl hydrocarbon receptor (AHR) and mediator 1 (MED1), two transactivators of Cyp1a2. Analysis of ChIP-seq data in the ENCODE (Encyclopedia of DNA Element) database identified association of CCCTC-binding factor (CTCF) with Ahr promoter in mouse livers. Both MED1 and CTCF are validated conserved miR-122 targets. Furthermore, depletion of Ahr, Med1, or Ctcf in Mir122 ${ }^{-/}$hepatocytes reduced Cyp1a2 expression. Pulse-chase studies found that CYP2E1 protein level is upregulated in LKO hepatocytes. Notably, miR-122 depletion sensitized differentiated human HepaRG cells to acetaminophen toxicity that correlated with upregulation of AHR, MED1, and CYP1A2 expression. Collectively, these results reveal a critical role of miR-122 in acetaminophen detoxification and implicate its therapeutic potential in patients with ALF. (Am J Pathol 2017, 187: 2758-2774; https://doi.org/10.1016/j.ajpath.2017.08.026)
Although acetaminophen is a widely used antipyretic and analgesic and is generally safe, it is a dose-related toxin in all mammals and causes approximately 1000 cases of acute liver failure (ALF) annually in the United States. ${ }^{1,2} \mathrm{~N}$ acetylcysteine (NAC) is a useful antidote for acetaminophen toxicity, but it is effective only if given within first 24 hours of acetaminophen ingestion. . $^{1,}$

Conjugation as a glucuronide or sulfate group is the main acetaminophen clearance pathway; a small fraction is metabolized by cytochrome $\mathrm{P} 450$ family 2 subfamily $\mathrm{E}$ member 1 (CYP2E1) and cytochrome P450 family 1 subfamily A member 2 (CYP1A2) to the highly reactive metabolite $N$-acetyl- $p$-benzoquinone imine (NAPQI). ${ }^{4}$ CYP2E1 is considered the key enzyme involved in

Supported in part by NIH grants DK088076 (K.G.) and R01A193244 (K.G.).

Dislcosures: None declared. 
acetaminophen bioactivation. However, metabolomics studies in the wild-type and Cyp $2 e 1^{-1-}$ mice surprisingly revealed that the contribution of CYP2E1 in acetaminophen metabolism decreases with increasing acetaminophen doses. ${ }^{5}$ Most of the NAPQI is detoxified by conjugation with glutathione (GSH); however, with GSH depletion, NAPQI covalently binds to protein thiols; these (acetaminophen-cysteine) adducts result in activation of Bax, which translocates to the mitochondrial outer membrane, where it forms pores with the help of other proapoptotic Bcl-2 family members, such as Bad, truncated Bid, and Bak. ${ }^{6}$ Intermembrane proteins, such as cytochrome $c$, Smac/DIABLO, apoptosis-inducing factor, and endonuclease $\mathrm{G}$, are released through these pores. ${ }^{7}$ Formation of NAPQI adducts also causes oxidative and nitrative stress, which results in mitochondrial membrane permeability transition., ${ }^{2,4}$ Mitochondrial membrane permeability transition causes uncoupling of oxidative phosphorylation, which amplifies oxidative and nitrative stress and results in depletion of ATP reserves. Endonuclease G cleaves cellular DNA; however, because of low ATP reserve, it initiates necrosis instead of apoptosis. ${ }^{4}$ Reactive oxidative and nitrative stress, as well as damage associated molecular patterns released from necrotic hepatocytes, can contribute to the induction of proinflammatory cytokines, which attract neutrophils to aggravate liver damage. ${ }^{4,8,9}$

miRNA-122 (miR-122) is a liver-specific conserved miRNA that regulates metabolic homeostasis and hepatitis $\mathrm{B}$ and $\mathrm{C}$ virus replication. ${ }^{10,11}$ However, miR-122 loss of function predisposes mice to develop spontaneous steatohepatitis and hepatocellular cancer, ${ }^{12,13}$ implicating its essential role in maintaining liver homeostasis. Being abundantly expressed in adult mammals and regulating the expression levels of many targets in hepatic cells, ${ }^{12-14}$ it is tempting to speculate that miR-122 also modulates drug toxicity, a major function of the liver.

Circulating miR-122 has been well established as an early and sensitive biomarker for liver injury caused by acetaminophen overdose. ${ }^{15,16}$ In fact, serum miR-122, highmobility group box protein 1 (HMGB1), and cytokeratin-18 are specific biomarkers for acetaminophen toxicity in ALF. ${ }^{15}$ However, the role of miR-122 in acetaminophen toxicity has not been studied in vivo. In this study, we investigated the role of miR-122 in acetaminophen-related liver toxicity using an experimental model of liver-specific miR-122 knockout (LKO) mice.

\section{Materials and Methods}

Mouse Strains, Animal Husbandry, and Treatment with Acetaminophen

The following inbred strains in the C57BL6J background were used: Mir122 LKO (Mir122 $2^{\text {loxP/loxP }}$ albumincyclization recombination ${ }^{+}$), Mir122 germline knockout (KO)

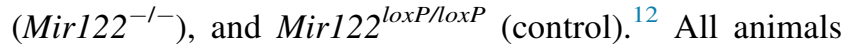
were housed in a temperature-controlled room under a 12 hours light/ 12 hours dark cycle and under helicobacter-free conditions and fed normal chow diet. All animal studies were reviewed and approved by the Ohio State University Institutional Laboratory Animal Care and Use Committee. Both male and female mice were used for experiments. For acetaminophen treatment, 10- to 12-week-old mice were fasted overnight followed by i.p. injection of acetaminophen at indicated dose dissolved in phosphate-buffered saline (PBS) at $37^{\circ} \mathrm{C}$ or PBS alone. Mice were allowed to have food and euthanized at indicated time points by $\mathrm{CO}_{2}$ asphyxiation. Blood was collected by cardiac puncture, and livers were isolated for histologic and molecular analysis. Unless mentioned otherwise, three to five male mice of each genotype were used for each treatment and time point.

\section{Serologic Analysis, Histologic Analysis, and Scoring Necrosis}

Alanine aminotransferase (ALT) level was measured in serum and primary hepatocyte culture supernatant using an ALT kit (catalog number A524-150; Teco Diagnostics, Anaheim, CA) following the manufacturer's protocol.

For histologic analysis, tissues were fixed in $4 \%$ paraformaldehyde and embedded in paraffin. Hematoxylin and eosin (H\&E) staining of liver sections was performed as described, ${ }^{12}$ and H\&E-stained slides were scored for necrosis in using the following scoring system: 0 , no necrosis; 1 , mild necrosis; 2 , moderate necrosis; 3 , severe necrosis; 4, 70\% to $80 \%$ liver is necrotic; and 5, whole liver is necrotic. A pathologist expert (W.M.L.) in drug-induced liver injury blinded to the experimental design performed necrosis scoring. Fisher exact tests were used to verify whether acetaminophen treatment caused significantly higher necrosis scores in LKO mice than in control mice at different time points. Holm's procedure was used for the adjustment of multiple comparisons.

\section{NAPQI Quantification}

NAPQI-cysteine adducts in livers and sera of control and LKO mice were measured using the high-performance liquid chromatography-electrochemical detection method. ${ }^{17}$

\section{RNA Isolation and Northern Blot Analysis}

The whole liver and serum RNAs (for Northern blot analysis) were isolated using TRIzol (catalog number 15596026; Thermo Fisher Scientific, Pittsburgh, PA) following the manufacturer's protocol and subjected to Northern blot analysis using ${ }^{32} \mathrm{P}$-labeled antisense miR-122 or an antisense 5S-rRNA oligo as described before. ${ }^{18}$ 


\section{Real-Time RT-PCR}

TaqMan miRNA Assay (Applied Biosystems, Foster City, CA) was used to quantify mature (catalog number 002245) and primary miR-122 expression (catalog number Mm03306556_pri) in DNase 1-treated liver, hepatocyte, or cellular RNA according to the manufacturer's instructions. Normalization was performed with Rnu6B (for miR-122) and 18S rRNA (for pri-miR-122). For mRNA expression analysis, DNase 1-treated total RNA was reverse transcribed into cDNA using a high-capacity cDNA reverse transcription kit (Applied Biosystems), and real-time PCR was performed using the SYBR Green assay method. The expression was normalized to that of Gapdh, $\alpha$-actin, or $18 \mathrm{~S}$ rRNA. All real-time reactions, including controls without cDNA, were run in triplicate in a thermocycler (Bio-Rad, Hercules, CA). Relative expression was calculated using the comparative threshold cycle method. Primer sequences are provided in Table 1. Mir-122 loxP/loxP and cyclization recombination genotyping primers and PCR conditions are described earlier. ${ }^{12}$
miRNA Mimics and Inhibitors

miRNA mimics and inhibitors used in this study are as follows: miRIDIAN mimic negative control (NC) (catalog number CN-001000-01), miRIDIAN mimic mmu-miR-122 mimic (catalog number C-310464-07), miRIDIAN hairpin inhibitor NC (catalog number IN-001005-01), and miRIDIAN hairpin inhibitor mmu-miR-122 antisense (catalog number IH-310464-08; Dharmacon, Lafayette, CO).

\section{SiRNAs}

siRNAs used in this study are as follows: si-Ahr (catalog number M-044066-01) and si-Med1 and si-NC (catalog number D-001206-13; Dharmacon).

\section{TaqMan Probes for Real-Time RT-PCR}

TaqMan probes for real-time RT-PCR used in this study are as follows: $\mathrm{mmu}-\mathrm{miR}-122$ (catalog number 002245) and

Table 1 RT-PCR Primer Used in This Study

\begin{tabular}{|c|c|}
\hline Gene symbol & Primer sequence \\
\hline \multicolumn{2}{|l|}{ Mouse } \\
\hline \multirow[t]{2}{*}{ Ctcf } & Forward: 5'-GCCCTCTCTCTTGATCGTAAAC-3' \\
\hline & Reverse: $5^{\prime}$-GTCCTTCCCAAGTCTGCATTTA-3' \\
\hline \multirow[t]{2}{*}{ Cyp2e1 } & Forward: 5'-ATAGAAGTTGGAACCTGCCCCC- $3^{\prime}$ \\
\hline & Reverse: 5'-AGCACСТCСТTGACAGCСTTGTAG-3' \\
\hline Сур1а1 & Forward: 5'-TGAGGCAGGGAGATGACTTCAAG-3' \\
\hline hnСур1a2 & Reverse: 5'-CCAGAACACTAAACAGAAGATGGCAG-3' \\
\hline \multirow[t]{2}{*}{ Сур1а2 } & Forward: 5'-CCGCTCGAGGCAGGGAGATGACTTCAAGGG-3' \\
\hline & Reverse: 5'-AACTATGTTTAAACTGATGGCTGTGGTGACTGTGTC-3' \\
\hline \multirow[t]{2}{*}{$h n A h r$} & Forward: 5'-GGCCAGGACCAGTGTAGAGC-3' \\
\hline & Reverse: 5'-СТTСТААТСССАТСТGCСAGG-3' \\
\hline \multirow[t]{2}{*}{ Actin } & Forward: $5^{\prime}-\mathrm{ACAACGGCTCCGGCATGT-3'}$ \\
\hline & Reverse: 5'-TCTTGCTCTGGGCCTCGTCAC-3' \\
\hline \multirow[t]{2}{*}{ Gapdh } & Forward: 5'-TCCTGCACCACCAACTGCTTAG-3' \\
\hline & Reverse: $5^{\prime}$-TGCTTCACСАССТTCTTGATGTC-3' \\
\hline \multirow[t]{2}{*}{$18 \mathrm{~S}$} & Forward: $5^{\prime}-\mathrm{TGACGGAAGGGCACCACCAG-3^{ \prime }}$ \\
\hline & Reverse: $5^{\prime}-$ TCGCTCCACCAACTAAGAACGGC-3' \\
\hline \multicolumn{2}{|l|}{ Human } \\
\hline \multirow[t]{2}{*}{ CTCF } & Forward: 5'-TACAAACACACCCACGAGAAG-3' \\
\hline & Reverse: $5^{\prime}$-CTCCAGTATGAGAGCGAATGTG-3' \\
\hline \multirow[t]{2}{*}{$A H R$} & Forward: 5'-TCAAGTCAAATCCTTCCAAGCG-3' \\
\hline & Reverse: 5'-CCGTTTCTTTCAGTAGGGGAGG-3' \\
\hline
\end{tabular}


Table 2 Primers Used for Luciferase Assay

\begin{tabular}{ll}
\hline Gene symbol & Primer sequence \\
\hline Ctcf-luc & Forward: 5'-CCGCTCGAGTTGCTCGGCACCAGGACTATTG-3' \\
Ctcf-mut-luc & Reverse: 5'-AAGAATGCGGCCGCAAGGTTCAAACGCTGGCTCC-3' \\
Med1-luc & Forward: 5'-CTCTCTCTTGATCGTAAACCTGAGGTGAACGGCCACGGGTTTCCC-3' \\
& Reverse: 5'-GGGAAACCCGTGGCCGTTCACCTCAGGTTTACGATCAAGAGAGAG-3' \\
Med1-mut-luc & Forward: 5'-CCGCTCGAGAAAGTCTACATCCCAGCATT-3' \\
& Reverse: 5'-ATAAGAATGCGGCCGCTTTTAAGTGAACTATGGCTG-3' \\
& Forward: 5'-TTCAGACTTAAATGTGAGGTCTGTATGCTC-3' \\
& Reverse: 5'-GGGGAGCATACAGACCTCACATTTAAGTCT-3'
\end{tabular}

RNU6b (catalog number 001093; Life Technologies, Carlsbad, CA).

\section{Luciferase Assay}

Amplification and cloning of $3^{\prime}$-untranslated regions ( $3^{\prime}$-UTRs) to psiCHECK2 (Promega, Madison, WI) were performed as previously described. ${ }^{1} C T C F$ and MED1 $3^{\prime}$ UTRs harboring miR-122-binding sites were cloned into psiCHECK-2 (catalog number C8021; Promega) at the $3^{\prime}$ UTR region of Renilla luciferase at XhoI and NotI sites. psiCHECK-2 constructs were co-transfected with either control scramble RNA or miR-122 mimic RNA (25 nmol/L) by Lipofectamine 3000 in Hepa1-6 or HEK293T cells. Luciferase activities were measured by the Dual-Luciferase Reporter Assay System (catalog number E1980; Promega) 48 hours after transfection. Primer sequences used for luciferase assay are provided in Table 2.

\section{RNA Isolation and Northern Blot Analysis}

The whole liver and serum RNAs (for Northern blot analysis) were isolated using TRIzol (catalog number 15596026; Thermo Fisher Scientific, Pittsburgh, PA) following the manufacturer's protocol and subjected to Northern blot analysis using ${ }^{32} \mathrm{P}$-labeled antisense miR-122 or an antisense 5S-rRNA oligo as previously described. ${ }^{18}$

\section{Western Blot Analysis}

Whole cell or tissue extracts were prepared in the lysis buffer [50 mmol/L Tris $\mathrm{HCl}$ (pH 8.1), 10 mmol/L EDTA (pH 8.0), and $1 \% \mathrm{SDS}$ ] containing protease inhibitor cocktails (Sigma, St. Louis, MO) followed by sonication to shear DNA. Liver nuclei were isolated using sucrose density gradient centrifugation as previously described, ${ }^{19}$ and nuclear proteins were extracted in SDS lysis buffer. These extracts (20 to $50 \mu \mathrm{g}$ of protein) were subjected to immunoblotting with specific antibodies, and the signal was developed with ECL reagent (Thermo Fisher Scientific) on X-ray film or the Odyssey CLx Imaging System (LI-COR, Lincoln, NE) after incubation with appropriate secondary antibodies. Western blot signals were quantified by ImageJ software version 1.48 (NIH, Bethesda, MD; http://imagej.nih.gov/ij) following the online manual for X-ray film or Image Studio Software version 5. 2 for the Odyssey CLx Imaging System (LI-COR). The catalog number and source of antibodies used are provided in Table 3. Protein concentrations were measured using Protein Assay Dye Reagent (catalog number 5000006; BioRad) with bovine serum albumin as the standard.

\section{Cell Lines and Transfection}

HepG2, Hep3B, and H293T cell lines were obtained from ATCC (Manassas, VA) and cultured as recommended by the supplier. Drs. Gretchen Darlington and James Taylor

Table 3 Antibodies Used in This Study

\begin{tabular}{lll}
\hline Antibody & Vendor & \\
\hline CYP2E1 & Abcam, Cambridge, MA & Catalog no. \\
GAPDH & EMD Millipore, Billerica, MA & MAB374 \\
CYP1A2 & Santa Cruz Biotechnology, Dallas, TX & sc-53241 \\
AHR & Santa Cruz Biotechnology, Dallas, TX & Sc-5579 \\
MED1 & Santa Cruz Biotechnology, Dallas, TX & sc-8998 \\
Actin & Santa Cruz Biotechnology, Dallas, TX & sc-8432 \\
HNF4 & Santa Cruz Biotechnology, Dallas, TX & sc-8987 \\
HNF6 & Santa Cruz Biotechnology, Dallas, TX & sc-13050 \\
Ku-86 & Santa Cruz Biotechnology, Dallas, TX & SC-1484 \\
Ki-67 & Cell Signaling Technology, Danvers, MA & 12202 \\
Anti-mouse IgG, HRP linked & GE Life Sciences, Pittsburgh, PA & NA931V \\
Anti-rabbit IgG, HRP linked & GE Life Sciences, Pittsburgh, PA & NA934V \\
\hline
\end{tabular}

AHR, aryl hydrocarbon receptor; CYP1A2, cytochrome P450 family 1 subfamily A member 2; CYP2E1, cytochrome P450 family 2 subfamily E member 1; GAPDH, glyceraldehyde-3-phosphate dehydrogenase; HNF, hepatocyte nuclear factor; HRP, horseradish peroxidase; MED1, mediator 1. 
provided Hepa1-6 and Huh7 cells, respectively, and Dr. Bo Yu provided MHCCLM3 and MHCC97H cells. Cells culture were transfected with $50 \mathrm{nmol} / \mathrm{L}$ miRIDIAN mimic mmu-miR-122 (catalog number C-310464-07) or NC RNA (catalog number CN-001000-01) using Lipofectamine 3000 (catalog number L3000015; Thermo Fisher Scientific). Transfections were performed as described for siRNA. Hepa1-6 cells were transfected with $50 \mathrm{nmol} / \mathrm{L}$ miRIDIAN hairpin inhibitor specific for mmu-miR-122 (catalog number IH-310464-08) and control inhibitor (catalog IN-001005-01). Cells were harvested 48 to 72 hours after transfection for luciferase assay or RNA and protein isolation.

\section{Immunohistochemical Analysis}

For immunohistochemical analysis, slides were dewaxed and exposed to $95^{\circ} \mathrm{C}$ for 30 minutes for antigen retrieval. After incubation of liver sections with antibodies, the color was developed by the diaminobenzidine method and counterstained with hematoxylin.

\section{Tissues from Patients with ALF}

Frozen liver tissues from patients with ALF, all with nonacetaminophen causes (8 unknown, 1 mushroom), were obtained from the Department of Gastroenterology, Hepatology, and Endocrinology, Hannover Medical School, Hannover, Germany. Human specimens (blood and tissues) were collected after informed consent from patients with ALF. The study was performed as per the guidelines of and was approved by the ethics committee of Hannover Medical School. Four normal human liver biopsy specimens served as controls. The serum ALT, aspartate transaminase, and international normalized ratio values of these patients are provided in Supplemental Table S1.

\section{Hepatocyte Isolation, in Vitro Culture, Transfection, and Treatment with Acetaminophen}

Hepatocytes were isolated as described previously. ${ }^{20}$ Briefly, miR-122 KO or wild-type mice ( 25 to $30 \mathrm{~g}$ ) were anesthetized with ketamine and xylazine was injected i.p. Livers were perfused with $30 \mathrm{~mL}$ of perfusion buffer (catalog number 17701038; Thermo Fisher Scientific) $(5 \mathrm{~mL} /$ minute $)$ and then with $50 \mathrm{~mL}$ of warm $\left(37^{\circ} \mathrm{C}\right)$ liver digestion buffer (catalog number 17703034; Thermo Fisher Scientific) via the portal vein. The livers were aseptically removed to a sterile Petri dish that contained Dulbecco's modified Eagle's medium at $4^{\circ} \mathrm{C}$ to stop digestion. The hepatocytes were released by peeling off the hepatic capsule and dispersed by shaking the digested liver in Dulbecco's modified Eagle's medium at $4{ }^{\circ} \mathrm{C}$, followed by passing through a $70-\mu \mathrm{m}$ strainer and collected by centrifugation at $50 \times g$ for 3 minutes at $4^{\circ} \mathrm{C}$. Hepatocytes were suspended in hepatocyte wash media (catalog number 17704024; Thermo Fisher Scientific) and subjected to purification on $90 \%$ Percoll density gradient at $200 \times g$ for 10 minutes. Purified hepatocytes were washed twice in hepatocyte wash media before suspending in Williams' E medium supplemented with 5\% serum and $1 \mathrm{mmol} / \mathrm{L}$ glutamine. The hepatocytes were counted, and viability was determined by trypan blue dye exclusion. The cells were plated on 6-well plate coated with rat tail type I collagen (BD Bioscience, San Jose, CA) at a density of $1 \times 10^{6}$ cells per well. For gene transfection, hepatocytes were washed the next day with PBS and incubated in HepatoZYME-SFM media (catalog number 17705021; Thermo Fisher Scientific). Lipofectamine 3000 (catalog number L3000015; Thermo Fisher Scientific) was used to transfect primary hepatocytes with scrambled siRNA (catalog number D-001206-13-05; Thermo Fisher Scientific) or gene-specific siRNAs. After 6 to 8 hours, media was replaced with HepatoZYME-SFM supplemented with $1.25 \mu \mathrm{g} / \mathrm{cm}^{2}$ of collagen I to provide a sandwich matrix. For acetaminophen treatment, hepatocytes were washed with PBS after 4 hours of plating and incubated with Williams' E media. Primary hepatocytes were treated with acetaminophen or PBS for different time points.

\section{Estimation of Concentrations of GSH and 0xidized GSH Metabolites in the Liver by Nuclear Magnetic Resonance}

Each frozen liver tissue with exact weight (within the 150- to 200-mg range) was recorded for nuclear magnetic resonance (NMR) data normalization. Frozen liver tissues were thawed on ice in $300 \mu \mathrm{L}$ of cold acetonitrile and 300 $\mu \mathrm{L}$ of cold milliQ water for 15 minutes and homogenized at $4^{\circ} \mathrm{C}$ in Bullet Blender (Next Advance Model Gold BB24-AU), with $300 \mu \mathrm{L}$ of $0.5-\mathrm{mm}$ zirconium oxide beads at level 8 for 3 minutes and repeated once. Next, $200 \mu \mathrm{L}$ of cold water was added to each sample and subjected to centrifugation at $13,000 \times g$ for 15 minutes at $4{ }^{\circ} \mathrm{C}$ to remove tissue debris and beads. The supernatant was then transferred to a $15-\mathrm{mL}$ conical tube, and $700 \mu \mathrm{L}$ of cold acetonitrile was added to each tube. Residual tissue debris was pelleted by centrifugation at $5000 \times g$ for 20 minutes at $4^{\circ} \mathrm{C}$ in a swinging rotor. The supernatant was then transferred to a fresh $15-\mathrm{mL}$ tube, and an additional $1 \mathrm{~mL}$ of cold acetonitrile and $0.55 \mathrm{~mL}$ of cold water were added. A total of $2 \mathrm{~mL}$ of cold chloroform was then added to each tube followed by vigorous vortexing and centrifugation at $5000 \times g$ for 20 minutes at $4{ }^{\circ} \mathrm{C}$ for phase separation. The aqueous phase was then transferred to a fresh tube and temporarily stored at $-20^{\circ} \mathrm{C}$. A total of 1.1 $\mathrm{mL}$ of cold water was added to the organic phase (to ensure the complete recovery of polar metabolites), followed by vortexing and centrifugation with the same parameters used for phase separation. The aqueous phase was then transferred and combined with the corresponding previous aqueous phase, which was then lyophilized 
and resuspended in $600 \mu \mathrm{L}$ of $50 \mathrm{mmol} / \mathrm{L}$ sodium phosphate buffer ( $\mathrm{pH}$ 7.4) in $\mathrm{D}_{2} \mathrm{O}$ and transferred to a $5-\mathrm{mm}$ NMR tube.

Two-dimensional ${ }^{13} \mathrm{C}-{ }^{1} \mathrm{H}$ HSQC spectra were collected at $298 \mathrm{~K}$ on a Bruker $850 \mathrm{MHz}$ AVANCE III spectrometer equipped with a cryogenically cooled TCI probe. A total of $512 \times 2048\left(\mathrm{~N}_{1} \times \mathrm{N}_{2}\right)$ complex points were collected with 16 scans per increment. All NMR data were zero-filled, Fourier transformed, and phase-corrected using NMRPipe. Identification of metabolites from the two-dimensional NMR spectra was performed using the online COLMAR database query (http://spin.ccic.ohio-state.edu/index.php/ colmar, last accessed June 28, 2017). The concentrations of GSH and oxidized GSH (GSSG) in the NMR tube (total volume of $600 \mu \mathrm{L}$ ) were calculated from peak intensities by comparison with standard spectra of 1 $\mathrm{mmol} / \mathrm{L} \mathrm{GSH}$ and $1 \mathrm{mmol} / \mathrm{L}$ GSSG, respectively. The absolute amounts of GSH and GSSG were then calculated and divided by the weight of each tissue sample as reported.

Treatment of Hepatocytes with Cycloheximide, Puromycin, and MG-132

Primary hepatocytes were isolated from WT and LKO mice and plated in collagen-coated 12-well plates at $80 \%$ confluence in Williams' E media supplemented with 5\% serum and $1 \mathrm{mmol} / \mathrm{L}$ glutamine. The next day cells were washed with PBS and incubated in HepatoZYME-SFM media. Cells were treated with PBS, cycloheximide $(20 \mu \mathrm{g} / \mathrm{mL})$ or puromycin $(40 \mu \mathrm{g} / \mathrm{mL})$, and dimethyl sulfoxide or MG$132(10 \mu \mathrm{g} / \mathrm{mL})$ and harvested at different time points for protein extraction and immunoblotting.

\section{Pulse-Chase Studies in Hepatocytes in Culture to Measure the Half-Life of CYP2E1}

For measuring the half-life of Cyp2e1, primary hepatocytes were isolated from WT and LKO mice. Cells were plated in collagen-coated 6-well plate at $80 \%$ confluency in Williams' E media supplemented with 5\% serum. The next day cells were washed with PBS three times and incubated for 2 hours in methionine- and cysteine-free DMEM that contained $10 \%$ dialyzed fetal bovine serum. A total of $100 \mu \mathrm{Ci}$ of ${ }^{35} \mathrm{~S}$ methionine was added to each well, and after 1 hour cells were washed with PBS and harvested (0 hours) or incubated with unlabeled media and harvested at different time points. Whole cell lysates in radioimmunoprecipitation assay buffer were subjected to immunoprecipitation with a Cyp2e1 antibody. Immunoprecipitated proteins were resolved by SDS-PAGE, transferred to nitrocellulose membrane, and subjected to autoradiography and immunoblotting.

\section{TUNEL Assay}

Paraffin embedded liver sections were deparaffinized and rehydrated for antigen retrieval. Terminal deoxynucleotidyl transferase-mediated dUTP nick-end labeling (TUNEL) assay was performed following manufacturer's protocol (catalog number 0-17-141; EMD Millipore, Billerica, MA).

\section{JNK Activity Assay}

c-Jun-N-terminal protein kinase (JNK) activity was measured in the liver extracts using GST-c-JUN peptide and $\mathrm{\gamma}^{32} \mathrm{P}-\mathrm{ATP}$ as substrates as previously described. ${ }^{21}$

\section{Statistical Analysis}

Real-Time RT-PCR and transfection assays were performed in triplicate. The data are presented as means \pm SD. Most of the experiments were performed at least three times with multiple replicates. Two-sample $t$-tests were used for the other two group comparisons. Statistical analysis of mouse survival was performed using the log-rank test after taking into consideration multiple comparisons with Holm's procedure. $P<0.05$ is considered significant.

\section{Results}

\section{Acetaminophen Overdose Suppresses mir-122 Expression}

To determine whether acute liver injury modulates the miR122 expression, we first measured its level in the livers of patients with ALF and controls. Significant down-regulation of miR-122 levels was observed in ALF biopsy specimens compared with non-ALF controls (Supplemental Figure S1A), suggesting that acute liver injury suppresses miR-122 expression. To determine whether drug toxicity modulates liver miR-122 expression in mice, we measured hepatic miR-122 levels in miR-122 loxP/loxP (control) mice treated with acetaminophen $(300 \mathrm{mg} / \mathrm{kg})$. Six hours after administration of acetaminophen, there was an approximately $40 \%$ reduction of miR-122 levels (Figure $1 \mathrm{~A}$ and Supplemental Figure S1B), whereas highly unstable precursor miR-122 was detectable only in PBS-injected mice. Acetaminophen toxicity also down-regulated primary miR122 levels as early as 4 hours after injection (Figure 1B), which correlated with a decrease in expression of hepatocyte nuclear factor (HNF)- $4 \alpha$ and HNF6, two key transcriptional activators of the Mirl22 gene at the RNA (Figure 1C) and protein levels (Figure 1D). The decrease in their protein levels, especially of HNF6, was evident as early as 2 hours after acetaminophen overdose (Supplemental Figure S1C). These results suggest that acetaminophen overdose inhibits miR-122 expression by suppressing these two key transcription factors.

As reported earlier, ${ }^{22}$ we also noted that the increase in serum miR-122 occurred as early as 2 hours of acetaminophen toxicity and was more pronounced than the elevation in serum ALT levels (Supplemental Figure S1D). To determine whether all three variants of miR-122 (21 to 23 nucleotides) 
A

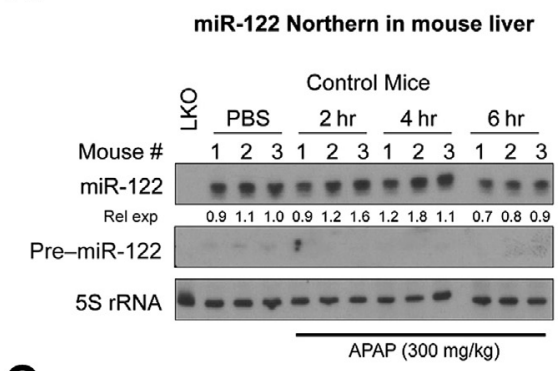

C

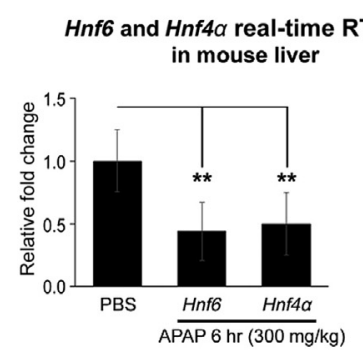

B

Primary miR-122 real-time RT-PCR in mouse liver

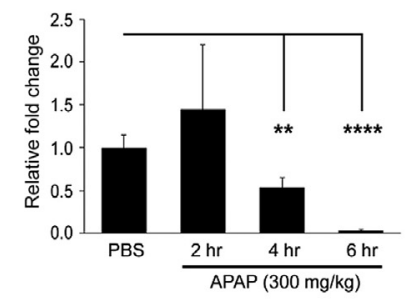

D

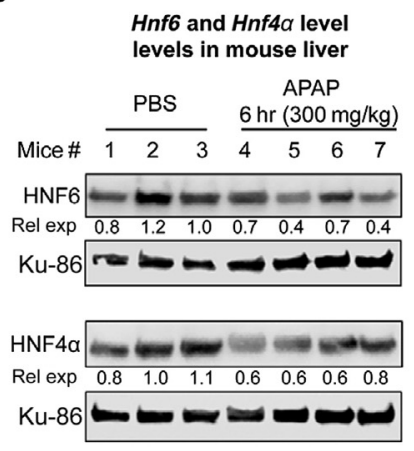

Figure 1 miRNA-122 (mir-122) expression is down-regulated in mouse livers on acetaminophen (APAP) overdose. A: Northern blot analysis of precursor and mature miR-122 in livers of control (Mir122 $2^{\text {loxP/loxP }}$ ) mice injected with acetaminophen or phosphate-buffered saline (PBS). B: Normalized primary miR-122 expression in livers of PBS- or acetaminophen-injected animals for indicated hours. C and D: Relative expression (rel exp) of Hnf6 and Hnfo RNA normalized to Gapdh (C) and proteins normalized to Ku-86 (D) in mice treated with acetaminophen for 6 hours. Data are expressed as means \pm SEM. $n=3$ to 5 mice of each genotype in each treatment group. ${ }^{* *} P<0.01,{ }^{* * * *} P<0.0001$ (two-tailed $t$-test). HNF, hepatocyte nuclear factor; LKO, liver specific miR-122 knockout. are released into circulation after acetaminophen overdose, we performed Northern blotting that revealed the presence of all three forms, among which the 23 nucleotides variant was most abundant in the serum of acetaminophen-injected control mice (Supplemental Figure S1E).

\section{Loss of miR-122 Sensitizes Mice to Acetaminophen Overdose}

Because the liver is the major organ involved in drug metabolism and acetaminophen overdose suppresses miR122 expression, we were curious to know whether the loss of miR-122 would modulate sensitivity to acetaminophen overdose. To this end, we treated ten 12 -week-old male mice with acetaminophen $(500 \mathrm{mg} / \mathrm{kg})$, which is lethal only to LKO mice, and monitored their survival. Nine LKO mice died within 19 hours of acetaminophen injection, and the remaining one died within 43 hours, whereas only 1 of 10 control mice died within this period (Figure 2A). We also observed higher mortality of male LKO mice at lower dose of acetaminophen $(300 \mathrm{mg} / \mathrm{kg})$ compared with control male mice given the same dose (Supplemental Figure S2A). Higher mortality rate $(P<0.0001)$ of LKO mice correlated with increased liver damage, as demonstrated by elevated serum ALT levels in LKO mice after 4 hours $(P=0.04)$ and 6 hours $(P=0.002)$ of acetaminophen $(300 \mathrm{mg} / \mathrm{kg})$ exposure, which was more remarkable (12.7-fold more than the control mice) $\left(P=1.84 \times 10^{-6}\right)$ after 24 hours of drug $(150 \mathrm{mg} / \mathrm{kg})$ treatment (Figure 2B). A reduced dose of acetaminophen was used for 24 hours of treatment because LKO mice exhibited mortality within 24 hours at $300 \mathrm{mg} / \mathrm{kg}$ if acetaminophen (data not shown). Higher serum ALT levels in acetaminophen-treated LKO mice correlated with increased centrilobular necrosis compared with control mice (representative H\&E-stained liver sections shown in Figure 2C). Scoring necrotic areas in liver sections of mice treated with acetaminophen $(300 \mathrm{mg} / \mathrm{kg})$ showed excessive hepatocyte degeneration in LKO mice compared with the controls at 4 and 6 hours (Figure 2D). More pronounced necrosis occurred in LKO mice compared with control mice treated with acetaminophen $(150 \mathrm{mg} / \mathrm{kg})$ for 24 hours correlating with increased serum ALT levels (Figure 2B). Furthermore, significant elevation of NAPQI-cysteinyl adducts with cellular proteins both in the liver (Figure 2E) and serum of the mutant mice (Supplemental Figure S2B) correlated with increased susceptibility of the mutant mice to acetaminophen overdose.

We also quantified hepatic GSH levels by NMR in LKO and control mice treated with acetaminophen (Supplemental Figure S2C). NAPQI is detoxified primarily by reacting with GSH, thereby depleting cellular GSH. To our surprise, we found that the basal GSH level is more than threefold higher in the PBS-injected LKO mice than in wild-type mice. However, it gets depleted in both genotypes within 30 minutes of acetaminophen treatment (Figure 2F and Supplemental Table S2), suggesting rapid depletion of GSH in the LKO livers, which correlates with higher NAPQI levels in these mice (Figure 2E). These results indicate that although LKO livers have substantially higher GSH levels, GSH gets rapidly depleted because of increased NAPQI formation.

The increase in the phosphorylation of JNK, a marker of cellular stress response, ${ }^{23}$ was also observed in LKO livers 


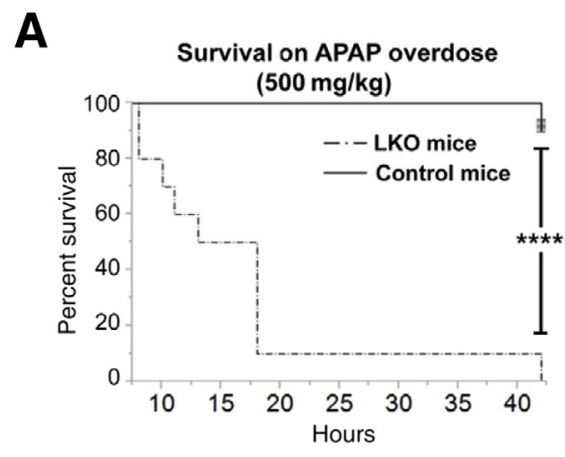

C

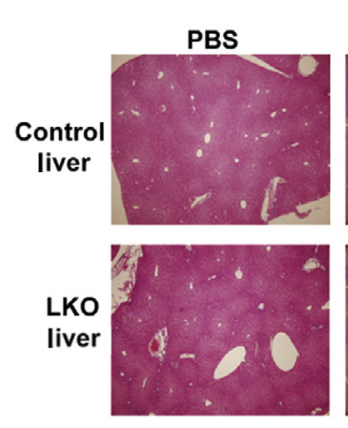

D

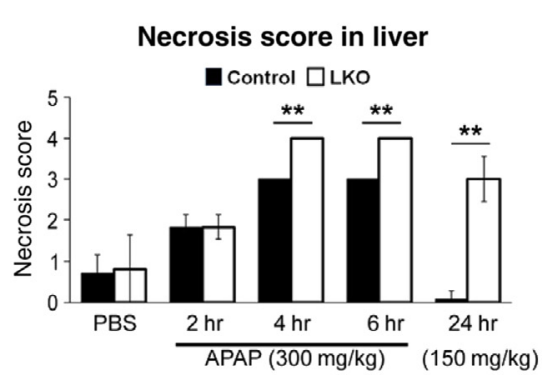

B

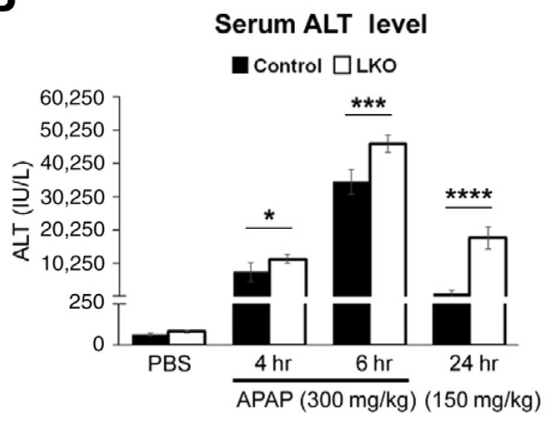

APAP (300 $\mathrm{mg} / \mathrm{kg})$
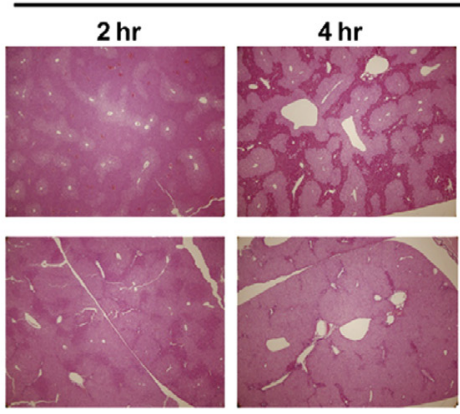

E
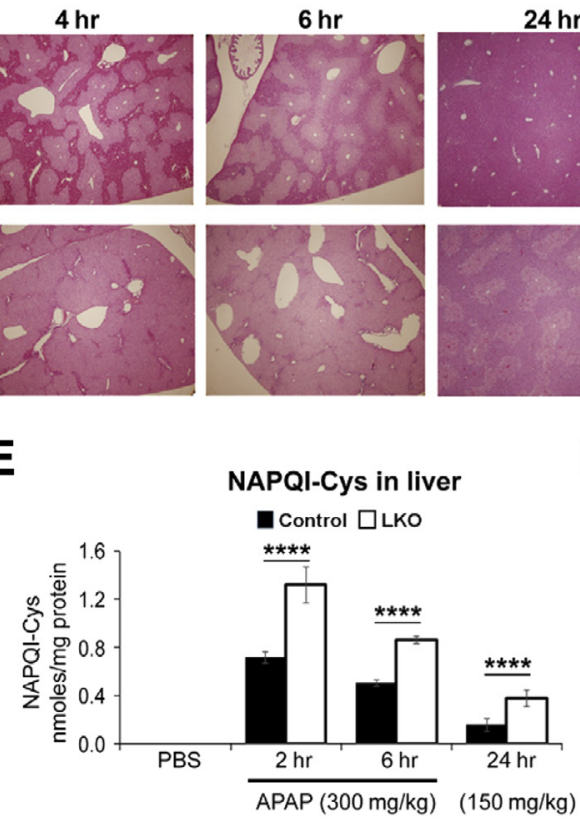

APAP $(150 \mathrm{mg} / \mathrm{kg})$ $24 \mathrm{hr}$
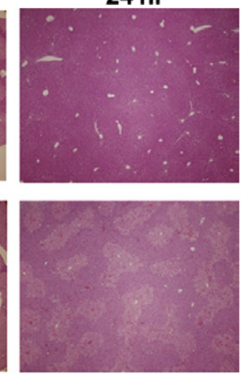

$\mathbf{F}$

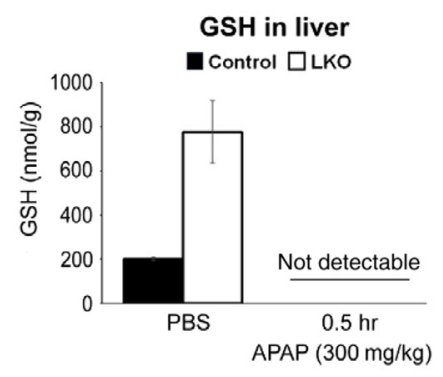

Figure 2 Liver-specific miRNA-122 (miR-122) knockout (LK0) mice are more susceptible to acetaminophen (APAP)-induced mortality and hepatotoxicity. A: Kaplan-Meier survival curve of control and LKO mice injected with acetaminophen. The mortality rate of overnight fasted mice injected with acetaminophen was monitored. B: Serum alanine aminotransferase (ALT) levels in acetaminophen overdosed animals. C: Representative images of hematoxylin and eosin (H\&E)-stained liver sections of mice treated with acetaminophen for different hours. D: Necrosis scores were evaluated from H\&E-stained liver sections. E and F: The levels of the hepatic $N$-acetyl-p-benzoquinone imine (NAPQI)-cysteine (Cys) adduct (E) and glutathione (GSH) (F) in acetaminophen overdosed mice. Data are expressed as means \pm SEM. $n=10$ of each genotype $(\mathbf{A}) ; n=4$ to 5 of each genotype (B and $\mathbf{D}-\mathbf{F})$. ${ }^{*} P<0.05,{ }^{* *} P<0.01,{ }^{* * *} P<0.001$, and $* * * * P<0.0001$ (two-tailed $t$-test). Original magnification, $\times 40$ (C). PBS, phosphate-buffered saline.

in acetaminophen overdosed mice (Supplemental Figure S3A). Notably, JNK activity remained higher in LKO mice even after 24 hours of acetaminophen treatment (Supplemental Figure S3B), indicating hepatocyte injury and death. TUNEL assay also revealed a greater number of hepatocytes with DNA strand breaks in LKO mice treated with acetaminophen for 24 hours (Supplemental Figure S4A). Increased hepatocyte death also resulted in more facilitated proliferation in LKO mice, as demonstrated by the higher population of Ki-67-positive hepatocytes in acetaminophen-treated LKO mice (Supplemental Figure S4B). We also observed higher mortality of female LKO mice $(P<0.0016)$ compared with control female mice subjected to acetaminophen toxicity (Supplemental Figure S5A). Lethal acetaminophen dose $(750 \mathrm{mg} / \mathrm{kg})$ in female LKO mice was higher than in males $(500 \mathrm{mg} / \mathrm{kg})$ because female mice are relatively resistant to the drug. ${ }^{24}$ Taken together, these results suggest a protective role of miR-122 against acute acetaminophen hepatotoxicity.

Hepatic Cyp1a2 and Cyp2e1 Levels Are Increased in miR-122 LKO Mice

Next, we sought to elucidate the mechanism of increased susceptibility of LKO mice to acetaminophen overdose initially focusing on CYP2E1 and CYP1A2, two key enzymes that oxidize acetaminophen to toxic NAPQI. To this end, we first looked at the microarray data of 8- to 10-weekold mouse livers (https://www.ncbi.nlm.nih.gov/geo; accession number GSE20610), which revealed higher 
A

Cyp1a2, Cyp2e1 real-time quantitative RT-PCR in fasted mouse liver

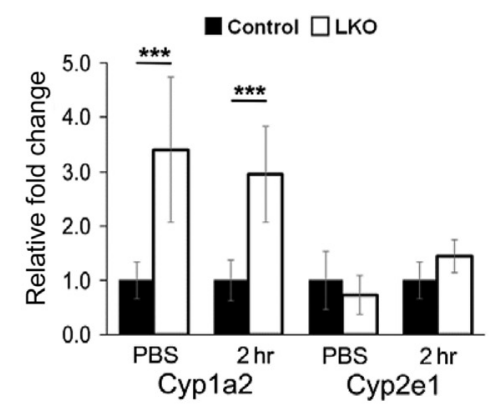

D

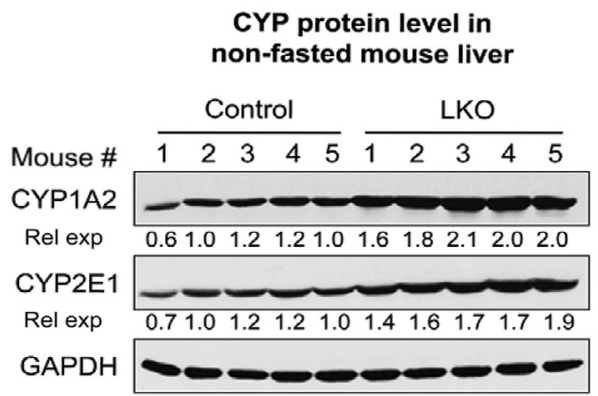

B

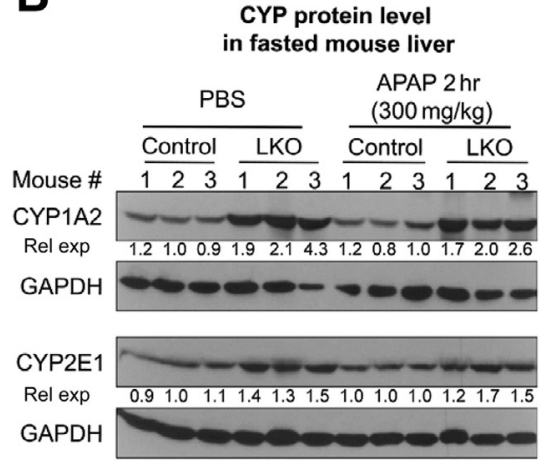

$\mathbf{E}$

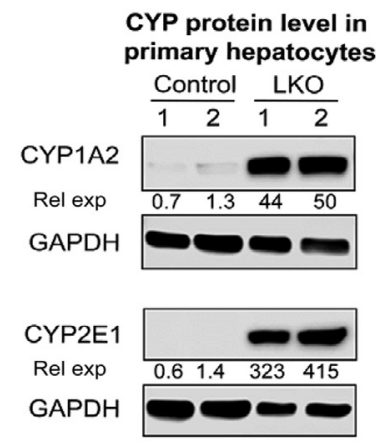

C

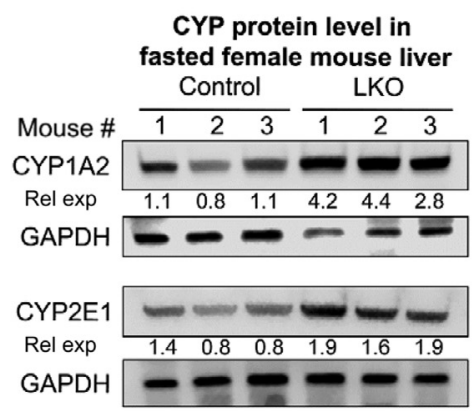

$\mathbf{F}$

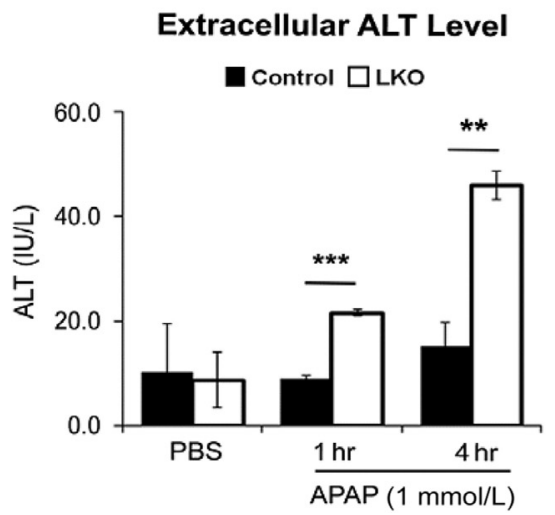

Figure 3 Basal cytochrome P450 family 2 subfamily E member 1 (CYP2E1) and cytochrome P450 family 1 subfamily A member 2 (CYP1A2) levels are higher in liver-specific miRNA-122 (miR-122) knockout (LK0) livers compared with the controls liver. A and B: Hepatic Cyp1a2 and Cyp2e1 mRNA (A) and protein (B) levels in fasted male mice. C and D: Hepatic CYP protein levels in fasted female (C) and nonfasted male (D) mice. E: CYP expressions in hepatocytes in culture for 12 hours. F: Alanine aminotransferase (ALT) levels in culture supernatants of hepatocytes treated with phosphate-buffered saline (PBS) or acetaminophen for 6 hours. Hepatocytes from 2 mice of each genotype (age and sex-matched) were used. Data are expressed as means \pm SEM. $n=3$ to 5 of each genotype (A). ${ }^{* *} P<0.01,{ }^{* * *} P<0.001$ (two-tailed $t$-test). GAPDH, glyceraldehyde-3-phosphate dehydrogenase; rel exp, relative expression.

basal Cypla2 mRNA level in LKO mice compared with controls $\left(1.685\right.$ fold, $\left.P=3.075 \times 10^{-7}\right)($ GSE20610) without significant changes in Cyp2e1 (1.071-fold, $P=0$. 13). Indeed, Cypla2 but not Cyp2e1 RNA level was higher in LKO mice compared with control mice injected with PBS or acetaminophen $(300 \mathrm{mg} / \mathrm{kg}$ ) for 2 hours (Figure 3A). Surprisingly, both CYP1A2 and CYP2E1 proteins were elevated in LKO livers relative to controls injected with PBS and remained high even after acetaminophen treatment (Figure 3B and Supplemental Figure S5B), suggesting posttranscriptional regulation of CYP2E1 in the mutant livers. Basal levels of these two Cyp450s were also higher in the livers of nonfasted LKO male mice and in fasted female LKO mice compared with respective controls, suggesting that miR-122 regulates their expression in both sexes irrespective of the food intake (Figure 3, C and D, and Supplemental Figure S5, C and D). Furthermore, LKO hepatocytes in culture also showed higher CYP2E1 and CYP1A2 levels compared with the controls (Figure 3E), and were more susceptible to acetaminophen toxicity, as demonstrated by elevated
ALT levels in culture supernatants (Figure 3F) and increased hepatocyte death (Supplemental Figure S5E). These results suggest that upregulation of these two Cyp450s that increases NAPQI level (Figure 2E) is involved in the higher susceptibility of LKO mice to acetaminophen overdose.

\section{Derepression of Aryl Hydrocarbon Receptor and}

Mediator 1 Contributes to the Upregulation of Hepatic Cyp1a2 in miR-122 LKO Mice

To gain insight into the underlying mechanism of higher basal CYP1A2 and CYP2E1 levels in miR-122 depleted liver, we initially searched different miRNA target prediction databases. However, none of those predicted these two Cyp450s as miR-122 targets, suggesting their indirect regulation by miR-122. Hence, we hypothesized that the loss of miR-122 activates the Cypla2 gene by modulating expression or activity of a key transcription factor(s) and upregulates the CYP2E1 protein by enhancing its translation or stability. To test this notion, we initially measured 
A

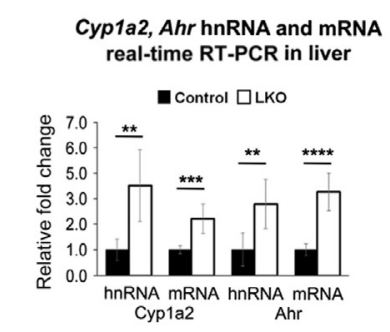

D Ahr, Cyp1a2 and Cyp1a2
real-time RT-PCR in Ahr depleted
LKO hepatocytes

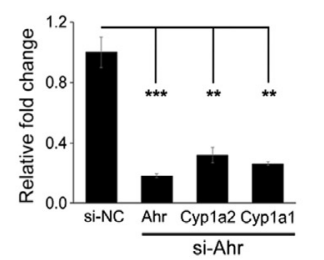

B

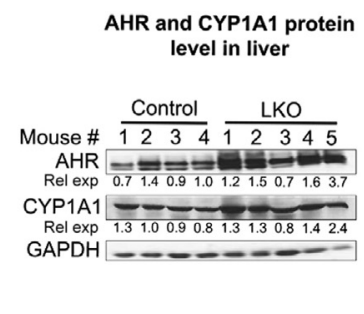

E
C Ahr and Cyp1a2 real-time RT-PCR in transfected hepatocytes

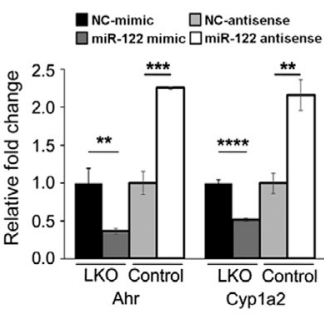

$\mathbf{F}$

\section{AHR protein level in SiRNA transfected} LKO hepatocytes

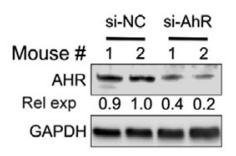

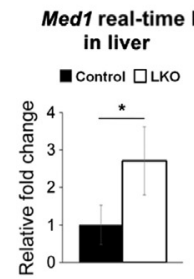

AHR level in liver nuclear extract

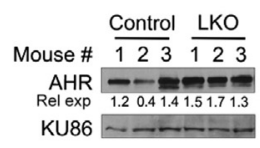

Figure 4 Expressions of aryl hydrocarbon receptor (AHR), a key transactivator of cytochrome P450 family 1 subfamily A member 2 (CYP1A2), and mediator 1 (MED1), a transcriptional co-activator are upregulated in liver-specific miRNA-122 (miR-122) knockout (LK0) livers. A: Expression of primary transcript (hnRNA) and mRNA of Cyp1a2 and Ahr in livers. B: AHR and cytochrome P450 family 1 subfamily A member 1 (CYP1A1) protein levels in liver lysates (left panel) and AHR and Ku-86 (normalizer) levels in nuclear extracts (right panel). C: Relative expression (rel exp) of Ahr and Cyp1a2 in Mir122-/- hepatocytes transfected with miR-122 mimic (122-S) or scrambled (NC-S) RNA and control hepatocytes transfected with miR-122 inhibitor or NC inhibitor 48 hours after transfection. D: Ahr and Cyp1a2 expression (left panel) and AHR protein level (right panel) in Mir122 $2^{-/}$hepatocytes transfected with Ahr siRNA (50 nmol/L). Expression of Ahr hnRNA and Cyp1a1 mRNA (normalized to Gapdh) and miR (normalized to Rnu6b). E: Med1 mRNA expression (left panel) and protein level (right panel) in livers. F: Cyp1a2 expression (left panel) and MED1 protein level (right panel) in miR-122 ${ }^{-/-}$hepatocytes transfected with Med1 siRNA. Hepatocytes from 2 mice of each genotype (age and sex matched) were used for Western and real-time RT-PCR(C, D, and F). Data are expressed as means

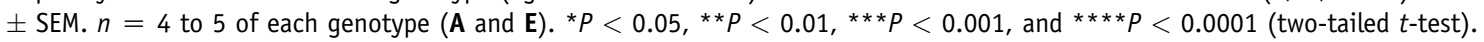

primary transcript or heteronuclear RNA (hnRNA), which showed upregulation of Cypla2 hnRNA in LKO livers relative to the controls (Figure 4A), suggesting transcriptional activation of Cypla2 and/or stabilization of the primary transcript.

To elucidate the underlying mechanism of upregulation of Cypla2 in LKO livers, we revisited our microarray data, which revealed a small but significant increase in RNA levels of aryl hydrocarbon receptor (AHR), a widely studied transactivator of Cypla2 and Cyplal, ${ }^{25}$ in LKO livers than in control livers $(1.3$-fold, $P=0.0055$ ). On binding to its ligands (endogenous or xenobiotics), AHR gets translocated to the nucleus and dimerizes with the co-activator, AHR nuclear translocator, to occupy Ahr response elements on target gene promoters to induce their expression. AHR activates both Cyplal and Cypla2 genes on binding to several $\mathrm{Ahr}$ response elements located between these two divergent genes. We hypothesized that upregulation of $A h r$ in miR-122 depleted livers might play a causal role in Cypla2 activation. Indeed, both RNA (3.3-fold) and protein (1.74-fold) levels of AHR (Figure 4, A and B), as well as CYP1A1 (1.4-fold) (Figure 4B), were elevated in LKO livers compared with controls. As expected, AHR levels in liver nuclear extracts were also elevated in LKO mice (Figure 4B). To find out whether miR-122 can modulate Ahr and Cypla2 expression, we transfected Mir$122^{-1-}$ hepatocytes in culture with miR-122 mimic or scrambled mimic and control hepatocytes with anti-miR122 or anti-NC (NC-AS) 6 hours after plating and measured their expression after 48 hours. We observed that ectopic miR-122 suppressed Ahr and Cypla2 RNA level in Mir-122-/- hepatocytes, whereas both were upregulated in the control hepatocytes depleted of miR-122 (Figure 4C). To evaluate AHR's role in Cyp1a2 regulation, we knocked down its expression in Mir-122 $2^{-1-}$ hepatocytes by transfecting siRNA, which resulted in $82 \%$ and $68 \%$ decreased $A h r$ and Cypla2 RNA levels after 48 hours (Figure 4D). As expected, Cyplal expression was also reduced by $74 \%$ in $A h r$ depleted hepatocytes. Although the AHR protein level was reduced by approximately $45 \%$ in siRNA transfected cells (Figure 4D), Cyp450 proteins could not be detected consistently in hepatocytes in culture for $>48$ hours.

Because it has been reported that mediator 1 (MED1), a transcriptional co-activator, upregulates Cypla 2 expression by interacting with constitutive androstane receptor, a nuclear hormone receptor, ${ }^{26}$ we entertained the possibility that MED1 could play a role in Cyp1a2 induction in LKO mice. Indeed, microarray data showed upregulation of 

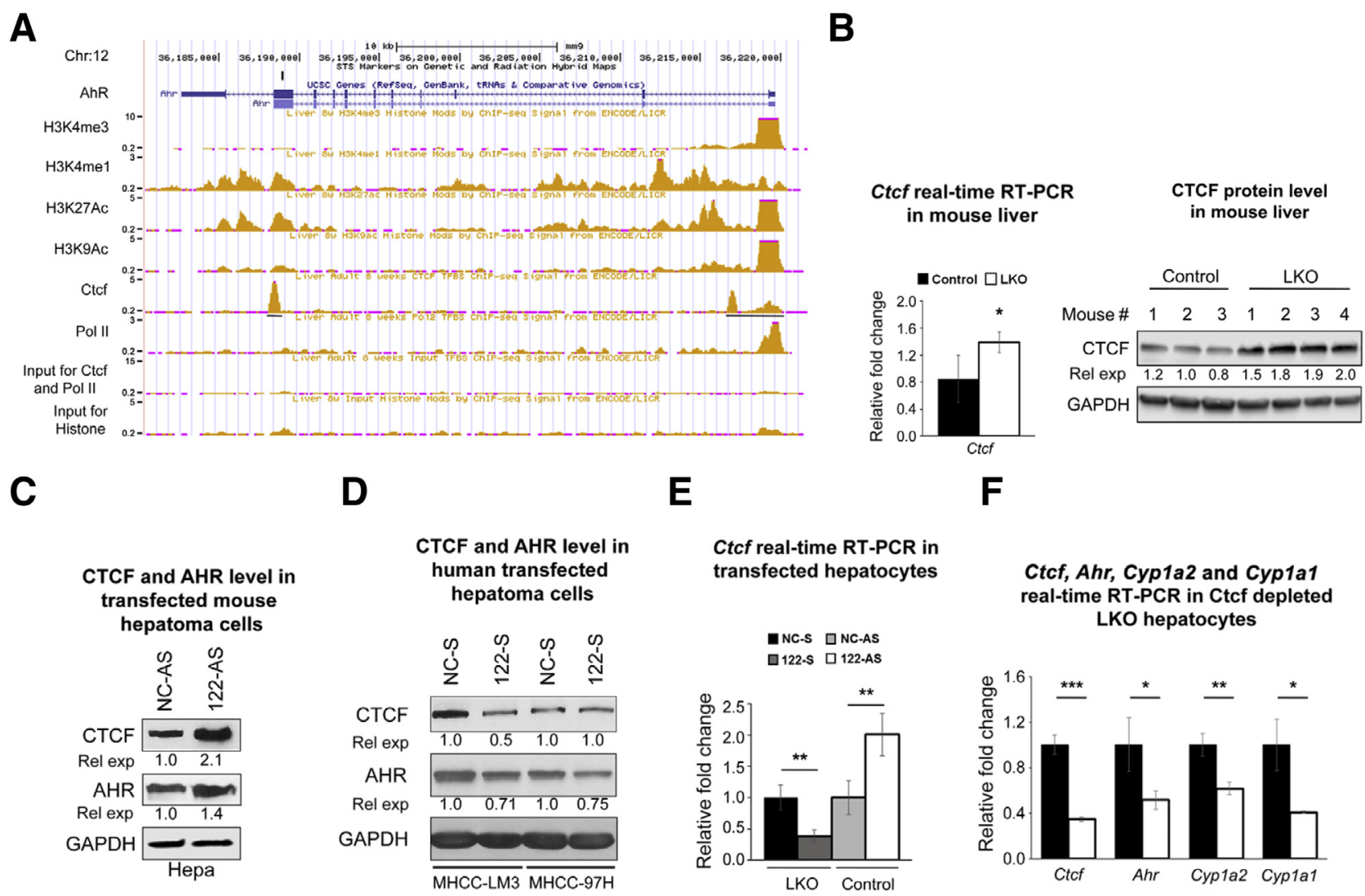

$\mathbf{F}$

Figure 5 miRNA-122 (miR-122) targets both mouse and human CCCTC-binding factor (CTCF) by binding at different sites. A: ChIP-seq data of polymerase II (Pol II), modified $\mathrm{H}_{3}$-histones associated with active promoters, and Ctcf on aryl hydrocarbon receptor (Ahr) promoter in 8-week-old mice livers downloaded from the ENCODE (Encyclopedia of DNA Element) database. B: Ctcf RNA and protein levels in mouse livers. C: CTCF and AHR levels in Hepa cells transfected with miR-122 inhibitor (122-AS) or scrambled inhibitor (NC-AS) for 48 hours (lysate pooled from 3 wells). D: CTCF and AHR levels in hepatocellular carcinoma cells transfected with miR-122 or NC mimic (lysate pooled from 3 wells). E: Relative expression (rel exp) of Ctcf and in Mir122 ${ }^{-1-}$ hepatocytes transfected with miR122 mimic (122-S) or scrambled (NC-S) RNA and control hepatocytes transfected with 122-AS or NC-AS 48 hours after transfection. F: Ctcf, Ahr, and cytochrome P450 family 1 subfamily A member 2 (Cyp1a2) expression in liver-specific miR-122 knockout (LKO) hepatocytes transfected with Ctcf siRNA. E and $\mathbf{F}$ : Hepatocytes from 2 mice of each genotype (age and sex matched) were used. Data are expressed as means \pm SEM. $n=3$ controls (B); $n=4$ LKO mice (B); $n=3$ to 5 mice of each genotype $(\mathbf{F}) .{ }^{*} P<0.05,{ }^{*} P<0.01$, and ${ }^{* * *} P<0.001$ versus control (two-tailed $t$-test). GAPDH, glyceraldehyde-3-phosphate dehydrogenase.

Med1 (1.3-fold, $P=0.0007)$ in miR-122 depleted livers, which was confirmed both at the RNA and protein levels (Figure 4E). Moreover, knock down of Medl reduced Cyp1a2 expression in LKO hepatocytes (Figure 4F). Collectively, these results demonstrate that upregulation of $A h r$ and Medl plays a key role in Cypla2 induction in LKO livers.

miR-122 Regulates Expression of Ahr and Med1 by Distinct Mechanisms

Next, the obvious question was how miR-122 regulates $A h r$ and Medl expression. Lack of miR-122-binding sites in mouse Ahr $3^{\prime}$-UTR or coding exons indicated that it is not directly regulated by miR-122. Upregulation of both $A h r$ hnRNA and mRNA levels suggested that $A h r$, like Cypla2, is also transcriptionally activated in miR-122 depleted livers (Figure 4A). To identify a potential transactivator(s) of $A h r$, we searched the ENCODE (Encyclopedia of DNA Element) database in the University of California, San Francisco genome browser. ${ }^{27}$ Indeed, ChIP-seq data ${ }^{28}$ identified the strong association of Ctcf (CCCTC-binding factor) with the promoter, immediate downstream region of the transcription start site and within intron 8 of $A h r$ gene in 8-week-old mouse livers (Figure 5A). Strong occupancy of RNA polymerase II and histone $\mathrm{H} 3 \mathrm{~K} 4 \mathrm{Me} 1 / \mathrm{Me} 3$ and $\mathrm{H} 3 \mathrm{~K} 9 \mathrm{Ac} /$ $\mathrm{K} 27 \mathrm{Ac}$ confirmed that $\mathrm{Ahr}$ is transcriptionally active in mouse livers (Figure 5A). CTCF, a validated miR-122 target in human, ${ }^{29}$ is a zinc finger protein that functions as a transcriptional activator, repressor, or insulator, depending on the chromosomal location of its cognate sites. ${ }^{30}$ Indeed, CTCF protein and RNA levels are elevated in LKO livers (Figure 5B). Moreover, depletion of miR-122 in mouse Hepa1-6 cells by transfecting anti-miR-122 oligo upregulated CTCF and AHR expression (Figure 5C and Supplemental Figure S6A), whereas miR-122 mimic 

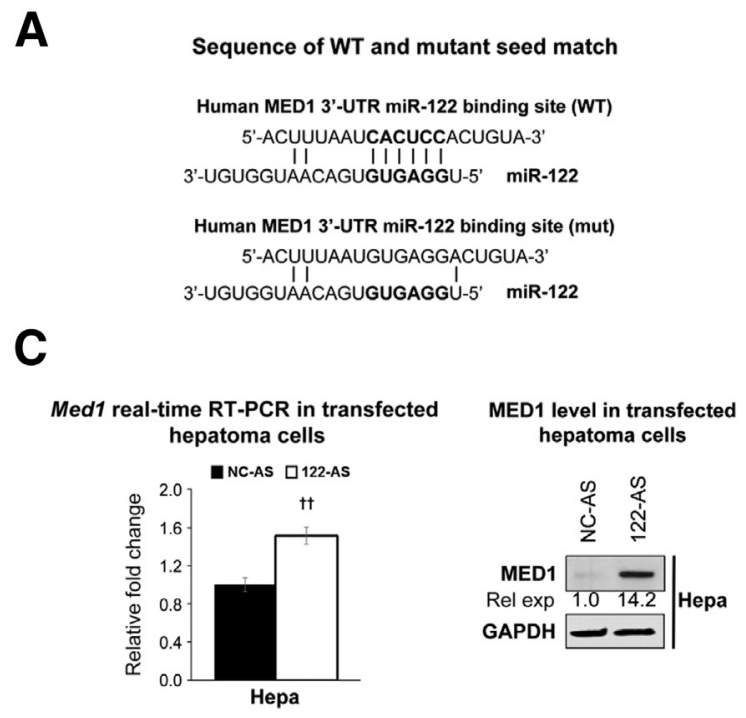

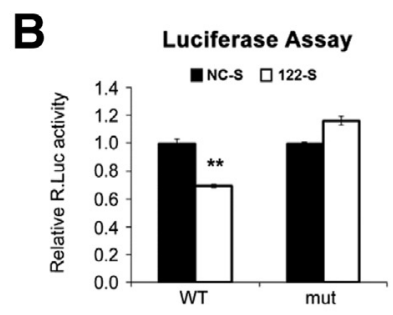

D

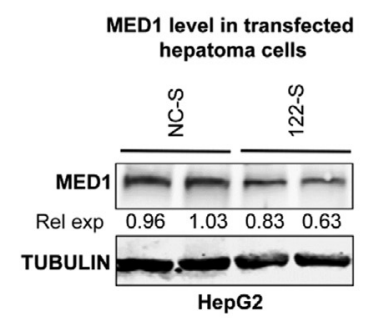

Figure 6 miRNA-122 (miR-122) suppresses mediator 1 (MED1) by interacting with a conserved site in its $3^{\prime}$-untranslated region ( $3^{\prime}$-UTR). A: Wildtype (WT) and miR-122 cognate site mutant (mut) in Med1 $3^{\prime}$-UTR. B: Luciferase activity in cells cotransfected with psi-CHECK2 MED1 $3^{\prime}$-UTR WT or psi-CHECK2 MED1 $3^{\prime}$-UTR mut with miR-122/NC mimic. C and D: MED1 level [normalized to glyceraldehyde-3-phosphate dehydrogenase (GAPDH)] in hepatocellular carcinoma cells transfected with miR-122/NC inhibitor (D) and in HepG2 cells transfected with miR-122/NC mimic. Data are expressed as means \pm SEM. $n=3 .{ }^{* *} P<0.01$ versus NC-S (two-tailed $t$-test); ${ }^{\dagger \dagger} P<0.01$ versus NC-AS (two-tailed $t$-test). rel exp, relative expression; R.Luc, Renilla luciferase. transfection suppressed their expression in human hepatoma (MHCCLM3 and MHCC-97H) cells (Figure 5D and Supplemental Figure S6, B-D). Similar results were observed in control and LKO hepatocytes transfected with anti-miR-122 and miR-122 mimic oligos, respectively (Figure 5E). To determine whether CTCF has any role in $A h r$ expression, we depleted it in LKO hepatocytes by transfecting siRNA, which resulted in the inhibition of not only $A h r$ but also Cypla2 expression (Figure 5F).

To find out whether miR-122 targets mouse CTCF, we searched different miRNA target prediction databases; TargetScan ${ }^{31}$ predicted a conserved miR-122-binding site in $3^{\prime}$-UTR of Ctcf. To confirm this, we performed luciferase reporter assay. For this purpose, we co-transfected the psi-CHECK2 vector harboring mouse Ctcf-3'-UTR region, including the miR-122-binding site (Supplemental Figure S6E) downstream of Renilla luciferase and miR-122 mimic or scrambled (NC RNA) in Hepa cells. Assay of Renilla luciferase activity after 48 hours showed its $24 \%$ reduction in cells that expressed ectopic miR-122 compared with the control, which was abrogated if the miR-122-binding site was mutated (Supplemental Figure S6F).

Because MED1 is also predicted as conserved in the miR-122 target (Figure 6A), we next sought to determine whether it is a true target. Indeed, co-transfection experiments showed that miR-122 mimic inhibited Renilla luciferase activity by $31 \%$ in cells expressing wild-type MED1 3'-UTR luciferase, which was reversed by transfecting psi-CHECK2 mutant MED1 3'-UTR (Figure 6B). Med1 RNA and protein expression were also upregulated on transfecting anti-miR-122 in Hepa cells (Figure 6C). In contrast, ectopic miR-122 expression in HepG2 cells reduced the MED1 level (Figure 6D). However, we could not measure Cyp1a2/1a1 expression in these cells because endogenous Cypla2/lal genes are silent in these cells because they could not be induced even after 2,3,7,8-tetrachlorodibenzo-p-dioxin treatment (data not shown), a potent activator of $A h r .^{32}$ Taken together, these results demonstrate CTCF and MED1 are miR-122 direct targets involved in Cypla2 expression in LKO livers.

\section{Cyp2e1 Protein Level Is Increased in miR-122 LK0 Livers because of Enhanced Translation}

Because CYP2E1 is upregulated in LKO livers only at the protein level (Figure 3B), we next attempted to address whether this is because of its increased translation and/ or protein stability. Pulse-chase studies found increased ${ }^{35} \mathrm{~S}$-methionine incorporation in $\mathrm{Mir}-122^{-1-}$ depleted hepatocytes compared with controls (Supplemental Figure S7A); however, the stability of the de novo synthesized protein was not reduced during a chase with cold methionine for several hours, suggesting its long half-life. Furthermore, no significant changes in CYP2E1 stability were noted in hepatocytes of either genotype on treatment with cycloheximide, a protein biosynthesis inhibitor or MG-132, a proteasome inhibitor (Supplemental Figure S7B), supporting the notion that the increase in CYP2E1 level in LKO livers is not attributable to its differential turnover or stability. Collectively, these results suggest that CYP2E1 translation is enhanced in miR122 LKO mice.

\section{Delivery of miR-122 Suppresses Acetaminophen- Induced Hepatotoxicity in miR-122 LKO Mice}

Next, we addressed whether miR-122 replenishment could rescue acetaminophen-induced liver toxicity in LKO livers. To test this, we delivered adenoassociated virus (AAV)$\mathrm{DJ}$ virus harboring miR-122 or AAV-DJ ${ }^{12}$ in the neonatal 
A

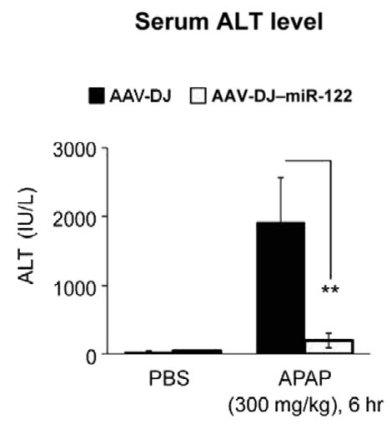

B

Liver miR-122 and serum ALT level in AAV-DJ and AAV-DJ-miR-122 injected LKO mice

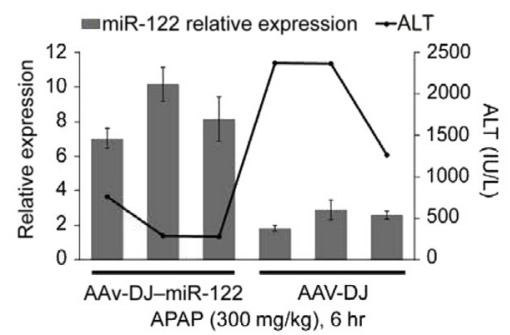

C

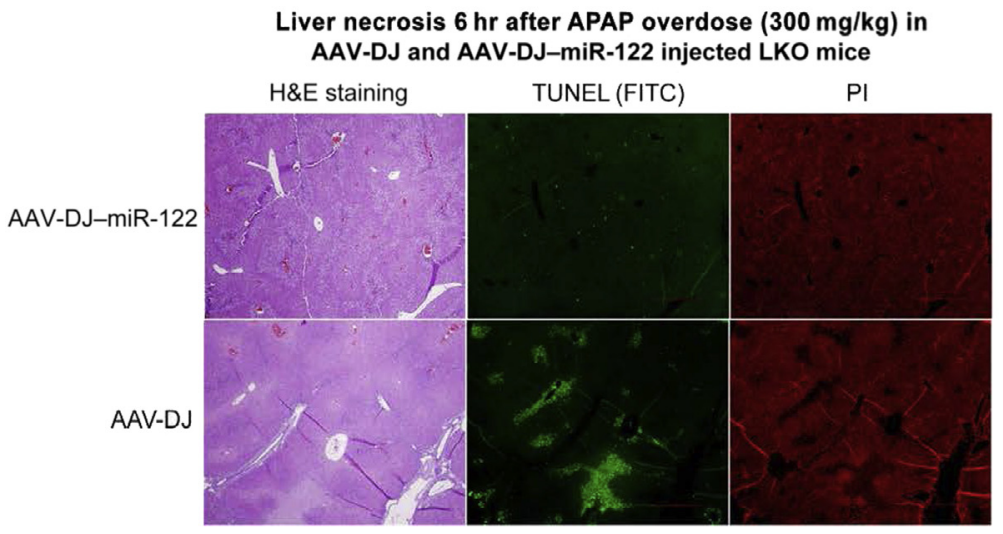

Liver miR-122 level in AAV-DJ or AAV-DJ-miR-122 injected LKO mice

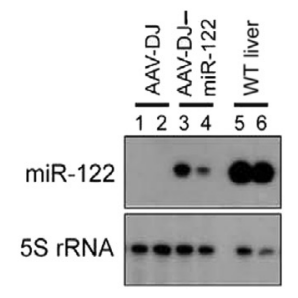

Figure 7 Adenoassociated virus (AAV)-DJ virus-mediated miRNA-122 (miR-122) delivery reduces liver damage in acetaminophen overdosed liver-specific miR-122 knockout (LKO) mice. A: Mean serum alanine aminotransferase (ALT) level in mice injected with AAV-DJ or AAV-DJ-miR-122 and treated with phosphate-buffered saline (PBS) or acetaminophen. B: Representative relative expression of miR-122 in the liver (bar diagram) and serum ALT level (line diagram) in mice injected with AAV-DJ or AAV-DJ-miR-122. C: Representative hematoxylin and eosin (H\&E) and terminal deoxynucleotidyl transferasemediated dUTP nick-end labeling (TUNEL) (green fluorescence), staining of liver sections of mice. Liver nuclei were stained with propidium iodide (PI) (red). D: Liver miR-122 level in LKO livers delivered miR-122 compared with control [wild-type (WT)] liver. Data are expressed as means \pm SEM. $n=3$ to 5 mice are used per genotype per treatment. ${ }^{*} P<0.01$ (two-tailed $t$-test). Original magnification: $\times 40$ (C). FITC, fluorescein isothiocyanate.

LKO mice as previously described (Supplemental Figure S8). ${ }^{33}$ As expected, the acetaminophen-induced serum ALT level was significantly reduced in mice delivered miR-122 (Figure 7A). In addition, the ALT level inversely correlated with miR-122 expression; the miR-122 level was elevated by 3.4 -fold $(P=0.0035)$ in mice delivered miR-122 compared with the controls (AAV-DJ) (Figure 7B). Of note, AAV-DJ delivery in LKO mice did not cause liver damage. Liver histologic analysis revealed that both groups developed liver necrosis on acetaminophen overdose; however, it was less pronounced in mice injected with AAV-DJ-miR-122 (Figure 7C). A lesser number of TUNEL-positive hepatocytes in AAV-DJ-miR122 injected mice compared with those that received AAVDJ indicates reduced DNA strand breaks on acetaminophen overdose (Figure 7C). The inability of exogenous miR-122 to completely block acetaminophen liver toxicity is probably because its expression was only $20 \%$ to $30 \%$ of the wild-type livers (Figure 7D). The results of this proofof-concept experiment suggest that acetaminophen hepatotoxicity in LKO mice could be partially rescued by miR-122 delivery.

\section{miR-122 Depletion Sensitizes Human HepaRG Cells to} Acetaminophen Toxicity

Next, we extended this study to differentiated human HepaRG cells that are reported to exhibit acetaminophen toxicity. ${ }^{34}$ These cells express miR-122, albeit at a lower level than mouse hepatocytes (Figure 8A). To find out the role of miR-122, if any, in acetaminophen detoxification in these cells, we transfected them with anti-miR-122 followed by acetaminophen $(20 \mathrm{mmol} / \mathrm{L})$ treatment 48 hours after transfection and assayed lactate dehydrogenase (LDH) activity in culture supernatants 24 hours later. As reported earlier, ${ }^{34}$ we observed a significant increase in the extracellular LDH activity on acetaminophen exposure compared with PBS treatment (Figure 8B). Notably, extracellular LDH activity in anti-miR-122 transfected cells was approximately fivefold higher than those transfected with NC (NCAS) RNA. Moreover, depletion of miR-122 in HepaRG cells resulted in upregulation of CTCF, AHR, MEDI, and CYP1A2 expression (Figure $8 \mathrm{C}$ ). In miR-122 mimic transfected cells, there was a trend in a decrease in acetaminophen-induced LDH release (Supplemental 


\section{A}

miR-122 expression in HepaRG cells and mouse hepatocytes

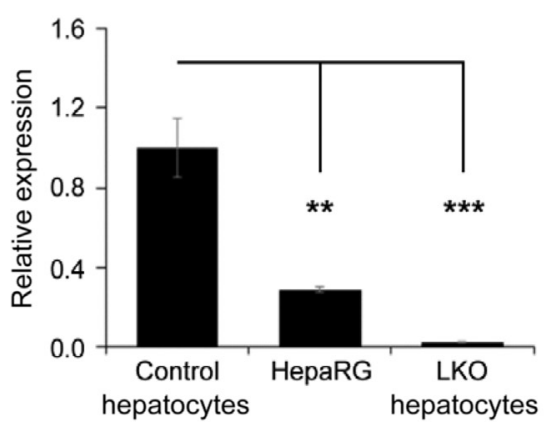

B

Extracellular LDH activity in HepaRG cells

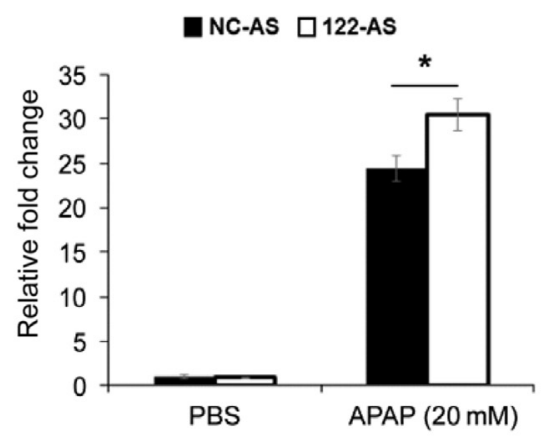

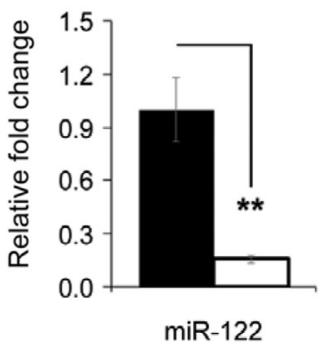
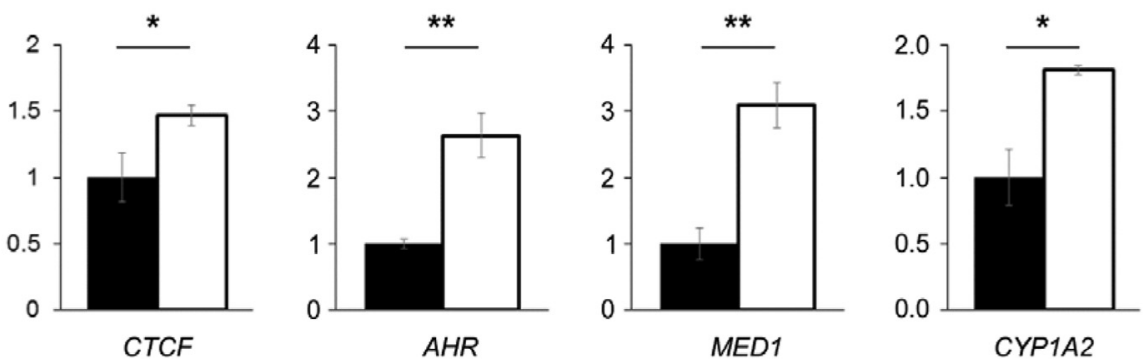

Figure 8 Differentiated HepaRG cells depleted of miRNA-122 (miR-122) are sensitive to acetaminophen toxicity. A: miR-122 expression in HepaRG cells and mouse hepatocytes. B: Lactate dehydrogenase (LDH) activity in culture supernatants of cells transfected with miR-122 (122-AS) or scrambled inhibitor (NC-AS) for 48 hours followed by acetaminophen treatment for 24 hours. C: Expressions of miR-122, CTCF, AHR, MED1, and CYP1A2 in cells transfected with 122-AS or NC-AS. Data are expressed as means \pm SEM. $n=3$. ${ }^{*} P<0.05,{ }^{*} P<0.01$, and ${ }^{* * *} P<0.001$ (two-tailed $t$-test). LK0, liver-specific miR-122 knockout; PBS, phosphate-buffered saline.

Figure S9A); however, it was not significant, probably because of the only approximately fourfold increase in the ectopic miR-122 level (Supplemental Figure S9B). Taken together, these results suggest that the sensitivity of HepaRG cells to acetaminophen could be modulated by miR-122. Of note, we did not find detectable LDH release from undifferentiated HepaRG cells after acetaminophen exposure probably because CYP1A2/2E1s were not detectable in these cells (not shown). Collectively, these results suggest that endogenous miR-122 protects HepaRG cells from acetaminophen toxicity.

\section{Discussion}

In the present study, we found that miR-122 expression is significantly reduced in human ALF livers and in mouse livers after acetaminophen overdose. Notably, the Mir-122 gene is transcriptionally suppressed in mouse livers early in acetaminophen toxicity probably because of a decrease in two key transcription factors, HNF4 $\alpha$ and HNF6. In addition, miR-122 regulates acetaminophen metabolism at least in part by controlling the expression of CYP1A2 and CYP2E1, two key enzymes involved in xenobiotic metabolism. Because of the low level of miR-122, derepressed CYP1A2 and CYP2E1 rapidly oxidize acetaminophen to NAPQI, deplete GSH, and increase NAPQIcysteinyl protein adduct formation, causing oxidative stress that culminates in hepatocyte death and liver toxicity. miR-122 may also regulate acetaminophen detoxification via glucuronidation and sulfation and conjugation of NAPQI with GSH. Quantification of acetaminophen metabolites by NMR revealed high acetaminophenglucuronide and acetaminophen-GSH levels in LKO livers compared with control livers (V.C. and B.Z., unpublished data), suggesting that miR-122 regulates its metabolism with multiple mechanisms. Microarray data revealed deregulation of expression of several Ugts (UDP-glucuronyltransferases), Sults (sulfotransferases), and Gstp2 (GSH-S-transferase p2) in miR-122 depleted livers, which may contribute to the altered acetaminophen metabolism and increased mortality rate of LKO mice to the drug overdose.

Our results unraveled a novel but complicated mechanism by which miR-122 regulates CYP1A2 expression through CTCF, AHR, and MED1. A key finding is that miR-122 regulates expression of AHR, a transcriptional activator, and MED1, a co-activator, in mouse and human hepatic cells. 
On the basis of our findings, we propose a model that depicts regulation of acetaminophen metabolism by miR-122 (Supplemental Figure S10).

Our study also found that miR-122 regulates CYP2E1 protein synthesis without affecting its mRNA level or protein stability. It has been reported that the regulation of CYP2E1 expression occurs at the translational and posttranslational levels. ${ }^{35,36}$ However, the precise mechanism of its regulation by miR-122 is yet to be understood. It is likely that a key factor(s) that promotes translation of Cyp2e1 mRNA may be upregulated in the miR-122 depleted liver. Alternatively, Cyp2el mRNA could undergo some posttranscriptional RNA modifications, such as methylation/demethylation, enhancing its translation in LKO livers.

After the discovery of NAC as a therapy for drug-induced liver injury in 1977, several agents, such as metformin, ${ }^{37}$ inhibitors of JNK, ${ }^{38}$ and S-nitrosoglutathione reductase, ${ }^{39}$ were found to have a protective role in experimental models; however, none were found to be more effective than NAC. Unfortunately, NAC therapy is effective only if administered within first few hours of the onset of liver toxicity. Thus, drugs that could be effective at later hours of toxicity are urgently needed. Recently, by screening a miRNA mimic library, Yang et $\mathrm{al}^{40}$ identified seven miRNAs, including miR-194, miR-125b, and miR-122, that protected mouse hepatocytes from acetaminophen-induced cell death. Moreover, miR-125b mimic delivery 1 hour after acetaminophen overdose increased survival of mice. We believe that certain miR-122 mimic alone or in combination with NAC could be therapeutically effective in restoring metabolic homeostasis that will inhibit necrosis and promote liver regeneration. Most of these new agents are tested in rodent models. It will be more informative to test these chemical inhibitors along miRNA-based therapeutics in the newly developed models, such as pig $^{41}$ and monkey, ${ }^{42}$ and ex vivo human liver model ${ }^{43}$ that mimic acetaminophen toxicity in humans.

Several mitogenic signaling pathways, such as IL-6/ STAT-3 and EGFR/c-Met/MAPK, Wnt/ $\beta$-catenin, NF- $\kappa B$, and ILK, are activated to promote liver regeneration after acetaminophen injury in mice. ${ }^{44}$ Significant increase in Ki67-positive hepatocytes in LKO mice after acetaminophen overdose (Supplemental Figure S4B) could be a compensatory mechanism to overcome excessive necrosis or because of inherent ability of Mirl $122^{-1-}$ hepatocytes to proliferate because of induction of growth-promoting factors (eg, $\beta$-catenin, CcnD1, CcnG1, c-Myc) that are upregulated in miR-122 depleted livers. ${ }^{9,45}$ Toxicogenomic studies have found that c-MYC and AP-1 are induced by acetaminophen and that $\mathrm{c}-\mathrm{Myc} / \mathrm{AP}-1-$ centered interactomes are the most significant networks of proteins associated with liver injury in humans. ${ }^{46}$ Increased basal c-MYC and E2F1 expression in LKO livers ${ }^{45}$ might also promote hepatocyte proliferation after acetaminophen overdose-induced hepatocyte death in these mice.
In summary, we found miR-122 as a novel regulator of acetaminophen-induced ALF. Our study established that miR-122 modulates drug metabolism at least in part by regulating CTCF, AHR, MED1, CYP1A2, and CYP2E1. Our in vitro and in vivo studies revealed the promising therapeutic potential of miR-122 against acetaminophen toxicity; hence, it can be explored as an antidote against drug-induced ALF. Because several anticancer drugs exhibit hepatotoxicity, it likely that this abundant miRNA in the liver might be involved in their metabolism by regulating many drug metabolizing enzymes. Moreover, regulation of CYP1A2 and CYP2E1 by miR-122 can be exploited in designing drugs for patients with hepatocellular carcinoma.

\section{Acknowledgments}

We thank Dr. Huban Kutay for technical assistance; Dr. Bo Wang and Juan Barajas for generating psi-CHECK2 CTCF 3'-UTR vector and psi-CHECK2 MED1 3'-UTR vector, respectively; Dr. Hemant K. Bid for Ki-67 immunohistochemistry data; and Dr. Joseph Luna for critically reading the manuscript.

V.C. designed, performed, and analyzed all experiments unless stated otherwise, organized the figures, and was involved in writing; K.-Y.T. designed, performed, and analyzed the experiments shown in Figure 6 and Supplemental Figure S5; C.-H.L. performed and analyzed Figures 1D, 5C, and 6D; B.Z., L.B.-L. and R.B. helped in generating NMR data for liver metabolites; N.W. injected AAV-DJ and AAV-DJ-miR-122; X.Z. performed statistical analysis of the data; D.Y. and N.J. generated data in patients with ALF; L.J. designed, performed, and analyzed Figure 2E and Supplemental Figure S2A; W.M.L. scored $\mathrm{H} \& \mathrm{E}$ slides for necrosis and was involved in writing the manuscript; K.G. conceived, coordinated the study, and wrote the manuscript; S.T. performed initial studies on the viability of mice on acetaminophen treatment and critically read the manuscript.

\section{Supplemental Data}

Supplemental material for this article can be found at https://doi.org/10.1016/j.ajpath.2017.08.026.

\section{References}

1. Lee WM: Drug-induced acute liver failure. Clin Liver Dis 2013, 17: $575-586$

2. Du K, Ramachandran A, Jaeschke H: Oxidative stress during acetaminophen hepatotoxicity: sources, pathophysiological role and therapeutic potential. Redox Biol 2016, 10:148-156

3. Dear JW, Antoine DJ, Park BK: Where are we now with paracetamol? BMJ 2015, 351:h3705

4. Hinson JA, Roberts DW, James LP: Mechanisms of acetaminopheninduced liver necrosis. Handb Exp Pharmacol 2010:369-405

5. Chen C, Krausz KW, Idle JR, Gonzalez FJ: Identification of novel toxicity-associated metabolites by metabolomics and mass isotopomer 
analysis of acetaminophen metabolism in wild-type and Cyp2e1-null mice. J Biol Chem 2008, 283:4543-4559

6. Bajt ML, Farhood A, Lemasters JJ, Jaeschke H: Mitochondrial bax translocation accelerates DNA fragmentation and cell necrosis in a murine model of acetaminophen hepatotoxicity. J Pharmacol Exp Ther 2008, 324:8-14

7. Bajt ML, Cover C, Lemasters JJ, Jaeschke H: Nuclear translocation of endonuclease $\mathrm{G}$ and apoptosis-inducing factor during acetaminopheninduced liver cell injury. Toxicol Sci 2006, 94:217-225

8. Woolbright BL, Jaeschke $\mathrm{H}$ : Role of the inflammasome in acetaminophen-induced liver injury and acute liver failure. J Hepatol 2017, 66:836-848

9. McGill MR, Jaeschke H: Mechanistic biomarkers in acetaminopheninduced hepatotoxicity and acute liver failure: from preclinical models to patients. Expert Opin Drug Metab Toxicol 2014, 10: $1005-1017$

10. Thakral S, Ghoshal K: miR-122 is a unique molecule with great potential in diagnosis, prognosis of liver disease, and therapy both as miRNA mimic and antimir. Curr Gene Ther 2015, 15:142-150

11. Szabo G, Bala S: MicroRNAs in liver disease. Nat Rev Gastroenterol Hepatol 2013, 10:542-552

12. Hsu SH, Wang B, Kota J, Yu J, Costinean S, Kutay H, Yu L, Bai S, La Perle K, Chivukula RR, Mao H, Wei M, Clark KR, Mendell JR, Caligiuri MA, Jacob ST, Mendell JT, Ghoshal K: Essential metabolic, anti-inflammatory, and anti-tumorigenic functions of miR-122 in liver. J Clin Invest 2012, 122:2871-2883

13. Tsai WC, Hsu SD, Hsu CS, Lai TC, Chen SJ, Shen R, Huang Y, Chen HC, Lee CH, Tsai TF, Hsu MT, Wu JC, Huang HD, Shiao MS, Hsiao M, Tsou AP: MicroRNA-122 plays a critical role in liver homeostasis and hepatocarcinogenesis. J Clin Invest 2012, 122: 2884-2897

14. Luna JM, Scheel TK, Danino T, Shaw KS, Mele A, Fak JJ, Nishiuchi E, Takacs CN, Catanese MT, de Jong YP, Jacobson IM, Rice CM, Darnell RB: Hepatitis C virus RNA functionally sequesters miR-122. Cell 2015, 160:1099-1110

15. Antoine DJ, Dear JW, Lewis PS, Platt V, Coyle J, Masson M, Thanacoody RH, Gray AJ, Webb DJ, Moggs JG, Bateman DN, Goldring CE, Park BK: Mechanistic biomarkers provide early and sensitive detection of acetaminophen-induced acute liver injury at first presentation to hospital. Hepatology 2013, 58:777-787

16. Dubin PH, Yuan H, Devine RK, Hynan LS, Jain MK, Lee WM: Micro-RNA-122 levels in acute liver failure and chronic hepatitis C. J Med Virol 2014, 86:1507-1514

17. Muldrew KL, James LP, Coop L, McCullough SS, Hendrickson HP, Hinson JA, Mayeux PR: Determination of acetaminophen-protein adducts in mouse liver and serum and human serum after hepatotoxic doses of acetaminophen using high-performance liquid chromatography with electrochemical detection. Drug Metab Dispos 2002, 30: 446-451

18. Kutay H, Bai S, Datta J, Motiwala T, Pogribny I, Frankel W, Jacob ST, Ghoshal K: Downregulation of miR-122 in the rodent and human hepatocellular carcinomas. J Cell Biochem 2006, 99:671-678

19. Wilkie GS, Schirmer EC: Purification of nuclei and preparation of nuclear envelopes from skeletal muscle. Methods Mol Biol 2008, 463: $23-41$

20. Wang AY, Lian LH, Jiang YZ, Wu YL, Nan JX: Gentiana manshurica Kitagawa prevents acetaminophen-induced acute hepatic injury in mice via inhibiting JNK/ERK MAPK pathway. World J Gastroenterol 2010, 16:384-391

21. Sakurai T, Maeda S, Chang L, Karin M: Loss of hepatic NF-кB activity enhances chemical hepatocarcinogenesis through sustained c-Jun N-terminal kinase 1 activation. Proc Natl Acad Sci U S A 2006, 103: 10544-10551

22. Wang K, Zhang S, Marzolf B, Troisch P, Brightman A, Hu Z, Hood LE, Galas DJ: Circulating microRNAs, potential biomarkers for drug-induced liver injury. Proc Natl Acad Sci U S A 2009, 106: $4402-4407$
23. Hanawa N, Shinohara M, Saberi B, Gaarde WA, Han D, Kaplowitz N: Role of JNK translocation to mitochondria leading to inhibition of mitochondria bioenergetics in acetaminophen-induced liver injury. J Biol Chem 2008, 283:13565-13577

24. McConnachie LA, Mohar I, Hudson FN, Ware CB, Ladiges WC, Fernandez C, Chatterton-Kirchmeier S, White CC, Pierce RH, Kavanagh TJ: Glutamate cysteine ligase modifier subunit deficiency and gender as determinants of acetaminophen-induced hepatotoxicity in mice. Toxicol Sci 2007, 99:628-636

25. Zhou SF, Wang B, Yang LP, Liu JP: Structure, function, regulation and polymorphism and the clinical significance of human cytochrome P450 1A2. Drug Metab Rev 2010, 42:268-354

26. Jia Y, Guo GL, Surapureddi S, Sarkar J, Qi C, Guo D, Xia J, Kashireddi P, Yu S, Cho YW, Rao MS, Kemper B, Ge K, Gonzalez FJ, Reddy JK: Transcription coactivator peroxisome proliferator-activated receptor-binding protein/mediator 1 deficiency abrogates acetaminophen hepatotoxicity. Proc Natl Acad Sci U S A 2005, 102: $12531-12536$

27. Rosenbloom KR, Sloan CA, Malladi VS, Dreszer TR, Learned K, Kirkup VM, Wong MC, Maddren M, Fang R, Heitner SG, Lee BT, Barber GP, Harte RA, Diekhans M, Long JC, Wilder SP, Zweig AS, Karolchik D, Kuhn RM, Haussler D, Kent WJ: ENCODE data in the UCSC Genome Browser: year 5 update. Nucleic Acids Res 2013, 41: D56-D63

28. Raney BJ, Dreszer TR, Barber GP, Clawson H, Fujita PA, Wang T, Nguyen N, Paten B, Zweig AS, Karolchik D, Kent WJ: Track data hubs enable visualization of user-defined genome-wide annotations on the UCSC Genome Browser. Bioinformatics 2014, 30: $1003-1005$

29. Xu H, He JH, Xiao ZD, Zhang QQ, Chen YQ, Zhou H, Qu LH: Liver-enriched transcription factors regulate microRNA-122 that targets CUTL1 during liver development. Hepatology 2010, 52: $1431-1442$

30. Kim S, Yu N-K, Kaang B-K: CTCF as a multifunctional protein in genome regulation and gene expression. Exp Mol Med 2015, 47:e166

31. Agarwal V, Bell GW, Nam JW, Bartel DP: Predicting effective microRNA target sites in mammalian mRNAs. Elife 2015, 4

32. Mimura J, Fujii-Kuriyama Y: Functional role of AhR in the expression of toxic effects by TCDD. Biochim Biophys Acta 2003, 1619: 263-268

33. Hsu SH, Delgado ER, Otero PA, Teng KY, Kutay H, Meehan KM, Moroney JB, Monga JK, Hand NJ, Friedman JR, Ghoshal K, Duncan AW: MicroRNA-122 regulates polyploidization in the murine liver. Hepatology 2016, 64:599-615

34. McGill MR, Yan HM, Ramachandran A, Murray GJ, Rollins DE, Jaeschke H: HepaRG cells: a human model to study mechanisms of acetaminophen hepatotoxicity. Hepatology 2011, 53:974-982

35. Kim SM, Wang Y, Nabavi N, Liu Y, Correia MA: Hepatic cytochromes P450: structural degrons and barcodes, posttranslational modifications and cellular adapters in the ERAD-endgame. Drug Metab Rev 2016, 48:405-433

36. Gonzalez FJ: The 2006 Bernard B. Brodie Award Lecture: Cyp2e1. Drug Metab Dispos 2007, 35:1-8

37. Du K, Farhood A, Jaeschke H: Mitochondria-targeted antioxidant Mito-Tempo protects against acetaminophen hepatotoxicity. Arch Toxicol 2017, 91:761-773

38. Gunawan BK, Liu ZX, Han D, Hanawa N, Gaarde WA, Kaplowitz N: c-Jun N-terminal kinase plays a major role in murine acetaminophen hepatotoxicity. Gastroenterology 2006, 131:165-178

39. Cox AG, Saunders DC, Kelsey PB Jr, Conway AA, Tesmenitsky Y, Marchini JF, Brown KK, Stamler JS, Colagiovanni DB, Rosenthal GJ, Croce KJ, North TE, Goessling W: S-nitrosothiol signaling regulates liver development and improves outcome following toxic liver injury. Cell Rep 2014, 6:56-69

40. Yang D, Yuan Q, Balakrishnan A, Bantel H, Klusmann JH, Manns MP, Ott M, Cantz T, Sharma AD: MicroRNA-125b-5p mimic inhibits acute liver failure. Nat Commun 2016, 7:11916 
41. Lee KC, Palacios Jimenez C, Alibhai H, Chang YM, Leckie PJ, Baker LA, Stanzani G, L Priestnall S, Mookerjee RP, Jalan R, Davies NA: A reproducible, clinically relevant, intensively managed, pig model of acute liver failure for testing of therapies aimed to prolong survival. Liver Int 2013, 33:544-551

42. Tamai S, Iguchi T, Niino N, Mikamoto K, Sakurai K, Sayama A, Shimoda H, Takasaki W, Mori K: A monkey model of acetaminopheninduced hepatotoxicity; phenotypic similarity to human. J Toxicol Sci 2017, 42:73-84

43. Schreiter T, Sowa JP, Schlattjan M, Treckmann J, Paul A, Strucksberg KH, Baba HA, Odenthal M, Gieseler RK, Gerken G,
Arteel GE, Canbay A: Human ex-vivo liver model for acetaminopheninduced liver damage. Sci Rep 2016, 6:31916

44. Apte U, Singh S, Zeng G, Cieply B, Virji MA, Wu T, Monga SP: Betacatenin activation promotes liver regeneration after acetaminopheninduced injury. Am J Pathol 2009, 175:1056-1065

45. Wang B, Hsu SH, Wang X, Kutay H, Bid HK, Yu J, Ganju RK, Jacob ST, Yuneva M, Ghoshal K: Reciprocal regulation of microRNA122 and c-Myc in hepatocellular cancer: role of E2F1 and transcription factor dimerization partner 2. Hepatology 2014, 59:555-566

46. Gunawan BK, Kaplowitz N: Mechanisms of drug-induced liver disease. Clin Liver Dis 2007, 11:459-475 